\title{
EFFECT OF FREE SURFACE AND FROUDE NUMBER ON THE PROTECTION LENGTH AND TURBULENCE IN THE COMPOUND TRANSITIONS THROUGH BRIDGES
}

\author{
Mahmoud.I.Attia ${ }^{1}$, Abdullah Alhomidan ${ }^{2}$ \\ ${ }^{1,2}$ Civil Engineering Dept., Faculty of Engineering, Hail University, Saudia Arabia \\ m.elshewey@yahoo.com,aabdull@hotmail.com
}

\begin{abstract}
An experimental study was carried out to investigate the effect of free surface, Froude and Reynolds numbers on the protection length and turbulence through compound transitions using Laser Doppler, in a rectangular channel. Measurements of turbulence are carried out along the compound transition, at different contraction ratios, at different bed slopes. Vertical transition in the bed were also changed. From the results, the protection length increases with the increase of the incoming Froude number, and increases with the increase of the relative height, while it increases with the increase of the contraction ratio. The steep slope has a major effect on the protection length. Free surface has a unique role in governing the turbulence in open channel flows. Within and downstream of the transition, the turbulence occurs primarily in the wall region. Within the transition, flow tends towards the critical state $\left(F_{r}\right.$ approaches close to 1) with a rise in the turbulence intensities in the free surface and the wall region which may be attributed to the flow tending towards critical state. At small values of Froude number $F_{r} \leq 0.22$, the effect of Froude number on turbulence intensities and the free surface waves negligible.
\end{abstract}

Keywords: Turbulence intensities- Laser Doppler-Protection length-Free surface-Relative height-Contraction ratioBottom slope-Froude number

\section{INTRODUCTION}

As the flow passes through a bridge, a channel transition in the form of contraction and subsequent expansion is involved. Flow in open channel transition being free surface flow, is governed both by gravity and the viscous forces. Hence the discussions are presented accounting both these effects in terms of Froude and Reynolds numbers. Open channel transitions have been studied extensively because of use in water resources engineering and their efficacy in reducing the energy loss in hydraulic structures. The information regarding the turbulence characteristics in the transition structures is somewhat scanty. It is well known that turbulent field in open channel transition can be regarded as the superposition of many eddies with different scales, and the fundamental characteristics of turbulence are the intersection among these structures. Paradoxically enough, the problem of separation of the main stream of flow at open channel transitions or an abrupt change of the boundary has attracted the attention of investigators since the earliest times and yet it remains one of the least understood and the most critical problems of fluid dynamics today. In designing a channel transition, it is always desirable to avoid excessive loss, to eliminate cross waves and the turbulence, to ensure smooth streamlined flow, to minimize standing waves, and to prevent the transition from acting as a choke influencing upstream flow. Thus, one of the purposes of this study of the turbulence in open channel transitions is to gain insight about the role of the effect of Froude and Reynolds numbers on the turbulence intensities in open channel transitions. Therefore, precise and accurate measurements of the mean and fluctuating flow quantities are carried out to study the depthwise variation of the turbulence intensities upstream, within and downstream of the transitions. The turbulent flow models in open channel flows are discussed by Chen and Jaw [2], Kim and Kline [7], Nezu and Nakagawa [15] and Rodi [16]. Experimental investigation on turbulent structure of back facing step flow have been reported by several investigators such as Nakagawa [13]. Simulation of turbulent flow at a Reynolds numbers, has been pointed by Antonia [1]. Measurements of turbulence in open channel flows have been reported by Nezu and Rodi [14], and Kironoto [8], Nezu and Nakagawa [12].Turbulent boundary layers have been reported by Clauser [3], and Kline and Reynolds [9]. Turbulence and secondary flow over sediment stripes has been studied by Mclelland and Ashworth [10]. The present research involves measurements of the mean and fluctuating flow quantities such as streamwise and vertical mean velocity components $\mathrm{u}^{\prime} / \mathrm{U}_{\mathrm{o}}$ and $\mathrm{v}^{`} / \mathrm{U}_{\mathrm{o}}$ and streamwise and vertical turbulence intensity components $\mathrm{u}^{\prime} / \mathrm{U}_{\mathrm{o}}$ and $\mathrm{v}^{`} / \mathrm{U}_{\mathrm{o}}$, and in a rectangular open channel with constant width. The 
measurements are carried out using a Laser Doppler Velocimetry (LDV) a non-intrusive Fibre-optic state of the art technique, in sudden and gradual channel transitions at channel contraction rations $\Delta \mathrm{b} / \mathrm{b} 0.3$ and 0.5 . The main objectives of the present study are, (a) To use the laser technique (LDV), which includes the date acquisition system, data processing to measure mean and fluctuating flow characteristics at different locations of the channel transitions, (b) To study the influence of free, Froude number $\left(F_{r}\right)$ and Reynolds number (Re) on the mean and fluctuating flow quantities such as streamwise and vertical mean velocities $\mathrm{u}^{`} / \mathrm{U}_{\mathrm{o}}$ and $\mathrm{v}^{`} / \mathrm{U}_{\mathrm{o}}$, streamwise and vertical turbulence intensities $\mathrm{u}^{\prime} / \mathrm{U}_{\mathrm{o}}$ and $\mathrm{v}^{\prime} / \mathrm{U}_{\mathrm{o}}$ upstream, within and downstream of the channel transitions, (c) A comparative study of the depthwise variation of the velocity components $\mathrm{u}^{\prime} / \mathrm{U}_{\mathrm{o}}$ and $\mathrm{v} / \mathrm{U}_{\mathrm{o}}$ (d) $\mathrm{A}$ comparative of the depthwise variation of turbulence intensities $u^{`} / U_{o}$ and $v^{\prime} / U_{o}$ at different cross sections along the centerline of the channel. The experiments were conducted at different values of $F_{r}$ and Re viz. $0.240,0.090$ and $0.5 \times 10^{5}$, and $0.15 \times 10^{5}$ respectively, generated by altering the depth of flow, and (e) To study the effects of channel contraction, bottom slope., approaching flow Froude number and vertical transition on the relative protection length downstream of the transition (sudden expansion).

\section{THEORETICAL STUDY}

The variables affecting the protection length (L) or the distance defined by spacing between section [2] and section [3] in Fig.(3), may be defined as: velocity of approach $\left(v_{u}\right)$, channel bottom with (B), flow width within transition zone (b), water depth of approach $\left(\mathrm{y}_{\mathrm{u}}\right)$, transition length $\left(\mathrm{L}_{\mathrm{t}}\right)$, channel bottom slope $\left(\mathrm{S}_{\mathrm{o}}\right)$, gravity acceleration $(\mathrm{g})$ and hump height within the transition(h). The functional relationship of the protection length downstream of sudden expansion could be written as:

$$
f_{1}\left(\mathrm{y}, \rho, \mathrm{v}_{\mathrm{u}}, \mathrm{y}_{\mathrm{u}}, \mathrm{h}, \Delta \mathrm{b}, \mathrm{L}_{\mathrm{t}}, \mathrm{S}_{\mathrm{o}}, \mathrm{L}\right)=0
$$

Using the dimensional analysis principles ( $\mathrm{Pi}$ theorem) based on $\mathrm{v}_{\mathrm{u}}, \mathrm{y}_{\mathrm{u}}$ and by repeating variables, the following dimensionless relationship of the relative protection length $(\mathrm{L} / \mathrm{b})$, could be expressed as:

$$
f\left[F_{u}, \frac{L}{y_{u}}, \frac{b}{y_{u}}, \frac{\Delta b}{y_{u}}, \frac{h}{y_{u}}, \frac{L_{t}}{y_{u}}, \mathrm{~S}_{\mathrm{b}}\right]
$$

Keeping in mind the properties of the dimensional analysis, dividing $\mathrm{L} / \mathrm{y}_{\mathrm{u}}$ by $\mathrm{b} / \mathrm{y}_{\mathrm{u}}$, to get $\mathrm{L} / \mathrm{b}, \Delta \mathrm{b} / \mathrm{y}_{\mathrm{u}}$ by $\mathrm{b} / \mathrm{y}_{\mathrm{u}}$ to get $\Delta \mathrm{b} / \mathrm{b}$, $\mathrm{h} / \mathrm{y}_{\mathrm{u}}$ by $\mathrm{b} / \mathrm{y}_{\mathrm{u}}$ to obtain $\mathrm{h} / \mathrm{b}$ and neglecting the effect of $\mathrm{L}_{\mathrm{t}}$ as it was kept constant during the course of the experimental work, the following relationship is obtained.

$$
\frac{\mathrm{L}}{\mathrm{b}}=\mathrm{f}_{2}\left[\mathrm{~F}_{\mathrm{u}}, \frac{\gamma_{\mathrm{u}}}{\mathrm{b}}, \frac{\mathrm{h}}{\mathrm{b}}, \frac{\Delta \mathrm{b}}{\mathrm{b}}, \mathrm{S}_{0}\right]
$$

In which $F_{u}$ is the approaching flow Froude number, $y_{u} / b$ is the relative approaching depth, $h / b$ is the relative height of the vertical transition and $\Delta \mathrm{b} / \mathrm{b}$ is the contraction ratio.

\section{EXPERIMENTAL SET UP AND EXPERIMENTAL PROGRAM:}

The experiments were carried out in a rectangular open channel that is $8.0 \mathrm{~m}$ long, $0.3 \mathrm{~m}$ width and $0.5 \mathrm{~m}$ height with glass wall $6 \mathrm{~mm}$ thick and thick and a steel plate bed. Fig. 1 shows layout of the test facility. The water is supplied from a constant head overhead tank to the flume at a desired discharge that is continuously monitored with an on-line orifice meter. The discharges were measured using a precalibrated orifice meter fitted in the feeding pipeline. And inline discharge control valve that is fitted into the main supplying pipeline was used to regulate the flow rate. Depth measurements were taken using a needle point gauge with a reading accuracy of $\pm 0.010 \mathrm{~mm}$. The flume side walls are made up of $6 \mathrm{~mm}$ thick glass sheets. A tail gate is provided at the downstream end of the flume to maintain a required water depth of the channel flow. The water is finally collected in a sump placed in the basement from where it is pumped back to the overhead tank by a $15 \mathrm{hp}$ pump. The experiments were carried out using five different lateral contraction ratios, $\Delta b / b$, of 0.1,0.2,0.3,0.4,0.5 and 0.6. Five different channel bottom positive slopes, $\mathrm{S}_{\mathrm{o}}$, of $0.00,0.005,0.01,0.015,0.02$ and 0.025 were used to illustrate the effect of bottom slope $S_{o}$ on the protection length $\mathrm{L} / \mathrm{b}$ due to local contraction. The slopes were selected based on the flume facilities. For each combination of lateral contraction ratio and bottom slope, five different flow rates ranging from about $45 \mathrm{lit} / \mathrm{sec}$ to $15 \mathrm{lit} / \mathrm{sec}$ were use. The upstream water depth was adjusted to produce a Froude number $F_{u}$ of approach ranging from 0.11 to 0.45 . The flow through the transition was always subcritical but it may changed to supercritical state just at the end of the transition or away from it, depending upon the incoming flow rate, the applied flume bottom slope $S_{o}$ and the contraction ratio $\Delta b / b$. For each combination of contraction ratio and bottom slope, the flow rate and the water surface profiles were measured. The effect of the vertical sudden transition on the protection length (L) was also studied, for a different lateral contraction ratios $\Delta b / b$ and a different bottom slope $S_{0}$. Five bed vertical transitions, within the lateral contraction, were used with relative heights of $\mathrm{h} / \mathrm{b}=0.1,0.2,0.3,0.4,0.5$ and 0.6 for each particular value of $\mathrm{h} / \mathrm{b}$, five different discharges were considered. Channel transitions were fabricated from transparent prespex sheets. The construction at the inlet and expansion at the outlet were, sudden.

With reference to the origin fixed at the channel bed and in the centre of the channel transition, traverse of measuring volume was run to obtain the profiles of both the mean velocity components and root mean square (RMS) of the turbulence intensities. The measuring points were closely spaced in the 
region of high velocity gradient. The Reynolds number based on the free stream velocity $4 \times 10^{4}$ which ensured the turbulent how for all the test conditions. Froude number of the free stream flow $F_{r}=0.24$, ensured the free stream flow to be subcritical. To obtain the vertical profiles the mean and fluctuating flow quantities, the measurements were conducted in the vertical plane at $\mathrm{z} / \mathrm{b}=0$ and $\mathrm{z} / \mathrm{b}=0.25$ at $\mathrm{Q}=40 \mathrm{1} / \mathrm{s}$.

\section{LASER MEASURING TECHNIQUE}

Laser Doppler Velocimetry (LDV). A 5 Watt Argon-ion Laser with two Laser beams; one blue $(488 \mathrm{~nm})$ and one green $(514.5 \mathrm{~nm})$, were focused at a measuring point from one side of the channel through on optical lens. Two burst spectrum Analyzers(BSA)were used to evaluate the Doppler frequencies. Subsequent computer analysis consisted of velocity bias averaging and outlier rejection. The number of samples taken at every point was 4000 bursts. This corresponds to a simple averaging time of about 80-100 seconds. The data rate was about 50-60 per second. Before acquiring the data, the LDV signal was checked for its regular Doppler burst that correspond to a particle passing through the measuring volume. The measurements were taken at different cross sections upstream, within, and downstream of the transition. Figure 3 shows the location grid of the measuring stations for all the channel transitions.

\section{RESULTS AND DISCUSSION}

The relationship between the relative protection length $\mathrm{L} / \mathrm{b}$ and the approaching flow Froude number $F_{u}$ is shown in Fig.4, for different bed slope $S_{o}$ at particular contraction ratios $\Delta b / b$ of $0.1,0.2,0.3,0.4,0.5$ and 0.6 , respectively. It can be noticed that the protection length $\mathrm{L} / \mathrm{b}$ increases as the bottom slope $S_{o}$ increases at particular $F_{u}$ and constant value of contraction. Also, $L / b$ increases as the Froude number $F_{u}$ increases, at particular slope and fixed value of contraction ratio. Comparing figures, it is obvious that as the contraction ratio $\Delta \mathrm{b} / \mathrm{b}$ increases from $\Delta \mathrm{b} / \mathrm{b}=0.1$ to $0.5, \mathrm{~L} / \mathrm{b}$ increases, considering particular bottom slopes. This observation is valid for all tested bottom slope and all tested range of $F_{u}$. These observations are attributed to the increase in the velocity of flow as the width of the channel is reduced from $b$ to $(b-\Delta b)$ leading to longer $\mathrm{L} / \mathrm{b}$ at the small contraction. Since the incoming flow is subcritical and the incoming unit discharge is smaller than the unit discharge through the transition zone, the depth of flow is lowered resulting in higher velocity because the pressure head is converted into velocity head. This higher velocity of flow that exits from the transition zone forces the jump to form away from the end of the transition leading to longer protection length $\mathrm{L} / \mathrm{b}$ compared to the cases of larger contraction ratios $\Delta b / b$. Similarly, the resulting high velocity due to the steeper bottom slope $S_{0}$ causes the jump to form away from the end of the transition zone yielding longer protection length compared to flatter slopes.
The relationships between $\mathrm{L} / \mathrm{b}$ and the approaching Froude number $F_{u}$ are presented in Fig.5 for different contraction ratios $\Delta \mathrm{b} / \mathrm{b}$ and particular slopes of $\mathrm{S}_{\mathrm{o}}=0.00,0.005,0.01,0.015,0.02$ and 0.025 respectively. Inspection of this figure indicates that the trend of variation of $\mathrm{L} / \mathrm{b}$ with $\mathrm{F}_{\mathrm{u}}$ is similar for different slopes and different contraction ratios $\Delta \mathrm{b} / \mathrm{b}$. It can be noticed that at fixed bottom slope $S_{0}$ and $\Delta b / b$, the relative protection $L / b$ increases as $F_{u}$ increases. It can be observed that the relative length of protection is longer for the bigger contraction ratio at particular $\mathrm{F}_{\mathrm{u}}$ when the bottom slope is kept constant.

Moreover, the present research investigated the effect of a vertical transition formed within the lateral constriction zone on $\mathrm{L} / \mathrm{b}$ for different Froude number $\mathrm{F}_{\mathrm{u}}$ and different bottom slope $S_{o}$ and fixed contraction ratio $\Delta b / b=30 \%$, as mid values of the tested ranges. The relationship between the relative protection length $\mathrm{L} / \mathrm{b}$ and the relative vertical transition $\mathrm{h} / \mathrm{b}$ for different Froude number $F_{u}$ at different bed slopes $S_{0}$ is presented in Fig.6. It can be easily observed that at fixed bottom slope and Froude number, the relative protection length $\mathrm{L} / \mathrm{b}$ increases as $\mathrm{h} / \mathrm{b}$ increases. Also, $\mathrm{L} / \mathrm{b}$ increases as the relative vertical height $h / b$ increases at the same Froude number $\mathrm{F}_{\mathrm{u}}$. This may be attributed to additional increase in the velocity head due to the transformation of the pressure head to velocity head when the flow meets the vertical transition. This can be simply explained as follows: since the approaching flow is subcritical and the incoming energy is higher than the energy at a downstream section, consequently, according to the specific energy principle, the depth of flow is lowered resulting in higher velocity which is turn leads to a longer projection length.

Root mean square (RMS) values of streamwise and vertical components of turbulence intensities $u^{`}$ and $v `$ are made nondimensional with respect to the steamwise mean free stream velocity $U_{0}$. Figs.8,9 and 10 depict the variation of non dimensional streamwise and vertical components of turbulence intensities $\mathrm{u}^{`} / \mathrm{U}_{\mathrm{o}}$ and $\mathrm{v}^{`} / \mathrm{U}_{\mathrm{o}}$ as a function of relative channel depth $y / y_{0}$ in sudden channel transitions for contraction ratios $\Delta \mathrm{b} / \mathrm{b}$ of 0.3 and 0.5 at different locations upstream, within and downstream the transitions along the length for different discharges (15-40)Lit/sec. Reynolds and Froude numbers are respectively $0.4 \times 10^{5}$ and 0.24 for free stream flow. The trend of variation of streamwise and vertical turbulence intensities $\mathrm{u}^{\prime} / \mathrm{U}_{\mathrm{o}}$ and $\mathrm{v}^{`} / \mathrm{U}_{\mathrm{o}}$ are similar in all the cases of channel transition. The trend of $\mathrm{u}^{\prime} / \mathrm{U}_{\mathrm{o}}$ and $\mathrm{v}^{`} / \mathrm{U}_{\mathrm{o}}$ upstream, within and downstream in all the cases of transition have higher values close to the bed, following a gradual fall in the wall region (wall effect) defined by $y / y_{0} \leq 0.2$, reaching minima in the middle region (core region) defined by $0.2<y / y_{0} \leq 0.6$. Turbulence intensities $\mathrm{u}^{\prime} / \mathrm{U}_{\mathrm{o}}$ and $\mathrm{v}^{`} / \mathrm{U}_{\mathrm{o}}$ rise gradually and then rapidly in the upper region (free surface region) defined by $y / y_{0}>0.6$ reaching the maximum at the free surface. Generally, the minimum streamwise and vertical 
turbulence intensities $\mathrm{u}^{`} / \mathrm{U}_{\mathrm{o}}$ and $\mathrm{v}^{`} / \mathrm{U}_{\mathrm{o}}$ always lie in the core region at the same location of the profiles of channel transition. The maximum turbulence intensities $\mathrm{u}^{\prime} / \mathrm{U}_{\mathrm{o}}$ and $v^{`} / \mathrm{U}_{\mathrm{o}}$ close to the bed or at the free surface depending on the location of the profile station at the same location of the of the profiles of transition. Also, as a comprehensive observation, it is noted that the streamwise turbulence $\mathrm{u}^{\prime} / \mathrm{U}_{\mathrm{o}}$ is always stronger compared to the vertical $\mathrm{v}^{\prime} / \mathrm{U}_{\mathrm{o}}$. In the wall region defined by $y / y_{0} \leq 0.2$, the turbulence intensities $u^{\prime} / \mathrm{U}_{\mathrm{o}}$ and $\mathrm{v}^{`} / \mathrm{U}_{\mathrm{o}}$ have substantially large magnitude closer to the wall (wall effect). With the increasing distance from the boundary, both the turbulence intensities decrease in wall region tending towards a minimum in the intermediate region (core region) defined by $0.2 \leq y / y_{0} \leq 0.6$, where the location of the minimum value of the turbulence consistently corresponds to that of maximum streamwise mean velocity $\overline{\mathrm{u}} / \mathrm{U}_{\mathrm{o}}$ where the velocity gradient is locally zero, reaching a higher value in the free surface.

Figs. 8 and 9 depict the variation of $\mathrm{u}^{\prime} / \mathrm{U}_{\mathrm{o}}$ and $\mathrm{v}^{`} / \mathrm{U}_{\mathrm{o}}$ in the transition for different $F_{r}$ and $R_{e}$ viz. 0.240,0.090; and $0.5 \times 10^{5}$ and $0.5 \times 10^{5}$, for free stream respectively at contraction ratio $\Delta b / b=0.3$, comparison of $u^{`} / U_{o}$ and $v ` / U_{o}$ upstream, within and downstream the transition, indicates that an increase in the Froude number and Reynolds number, decreases the turbulence intensities $u^{\prime} / \mathrm{U}_{\mathrm{o}}$ and $\mathrm{v}^{\prime} / \mathrm{U}_{\mathrm{o}}$ upstream and within the transition slightly with a slight increase in the turbulence intensities downstream of the transition in the expansion zone at the same flow conditions. This slight decrease in the turbulence intensities $u^{\prime} / U_{o}$ and $v^{\prime} / U_{o}$ with increasing $F_{r}$ and $R_{e}$ occur in the wall region and the free surface region and slight corresponding increase occurs in the downstream region. However, in the core region no noticeable change in the turbulence levels upstream, within and downstream region of the transition occurs. This increase or decrease in $F_{r}$ and $R_{e}$ is not associated with the drastic change in the nature of turbulence intensity profiles maintaining the similarity of turbulence profiles with $F_{r}$ and $R_{e}$ in the transition. This observation is consistent with the observation reported by Nezu and Nakagawa [14].

Figure 10 depict the turbulence intensity profiles along the depthwise and channel axis, for contraction ratio $\Delta b / b=0.5$. In the upstream region of the transition, the Froude and Reynolds numbers are 0.23 and $4 \times 10^{5}$ on an average respectively, turbulence is relatively lower compared to the turbulence within and downstream regions of the transition. Upstream of the entrance to the transition, surface waves were relatively mild. Upstream the transition, since the incoming flow is subcritical and turbulent as Froude and Reynolds numbers are 0.24 and $4 \times 10^{5}$ on average respectively, for $\mathrm{x} / \mathrm{b}<-1$, turbulence is relatively lower upstream of the transition. At the location of $\mathrm{x} / \mathrm{b}=-4, \mathrm{z} / \mathrm{b}=0 ; \mathrm{x} / \mathrm{b}=-3, \mathrm{z} / \mathrm{b}=0.25 ; \mathrm{x} / \mathrm{b}=-3, \mathrm{z} / \mathrm{b}=0$; and $x / b=-1, z / b=0$ at Reynolds number of $4 \times 10^{5}$ and the range of Froude number $0.218<\mathrm{F}_{\mathrm{r}}<0.229$, clearly, the trend of variation in streamwise and vertical turbulence intensities $\mathrm{u}^{\prime} / \mathrm{U}_{\mathrm{o}}$ and $\mathrm{v}^{\prime} / \mathrm{U}_{\mathrm{o}}$ are similar in all cases. In all the cases bath $\mathrm{u}^{\prime} / \mathrm{U}_{\mathrm{o}}$ and $\mathrm{v}^{\prime} / \mathrm{U}_{\mathrm{o}}$, the maximum turbulence intensities occur close to the bed, following a gradual fall in the wall region at $y / y_{0}<0.2$, reaching up to the free surface. It is also noted that the values of $\mathrm{u}^{`} / \mathrm{U}_{\mathrm{o}}$ and $\mathrm{v}^{`} / \mathrm{U}_{\mathrm{o}}$ are approximately constant in the core region. At $x / b=-1, z / b=0$, that is the centre just before the entrance of transition, the trend in variation curve of $u^{\prime} / \mathrm{U}_{\mathrm{o}}$ and $v^{`} / \mathrm{U}_{\mathrm{o}}$ is parallel. It has been observed during this experimentation, that surfaces waves play am important role in the turbulence production. Before the entrance to the transition, surface waves were relatively mild. Hence far away from the entrance, at $\mathrm{x} / \mathrm{b}=-4$ for instance, the turbulence intensities in the core region and at the surface are relatively low. The turbulence intensities are almost the same up to $\mathrm{x} / \mathrm{b}=-$ 2 for $\Delta \mathrm{b} / \mathrm{b}=0.5$. As the flow approaches the entrance, there is a gradual increase in the turbulence intensities $u^{\prime} / \mathrm{U}_{\mathrm{o}}$ and $\mathrm{v}^{`} / \mathrm{U}_{\mathrm{o}}$ in the core region as well as at the surface, with a subsequent fail in water depth within the transition. The minimum depth of water occurs approximately at the centre. The turbulence intensities at the free surface reach a large value of about $\mathrm{u}^{\prime} / \mathrm{U}_{\mathrm{o}} \approx 30 \%$ and $\mathrm{v}^{\prime} / \mathrm{U}_{\mathrm{o}} \approx 23 \%$ at the centre compared about $10 \%$ and $9 \%$ of the corresponding values at the free water surface is primarily due to oblique waves that are generated within the transition. The vicinity of the upstream corner of the transition a likely location separation at $\mathrm{x} / \mathrm{b}=-1, \mathrm{z} / \mathrm{b}=0.25$, turbulence levels are substantially higher compared to the one at centre $\mathrm{z} / \mathrm{b}=0$ at the location. The trend $\mathrm{u} / \mathrm{U}_{\mathrm{o}}$ and $\mathrm{v}^{`} / \mathrm{U}_{\mathrm{o}}$ are similar in the nature. At the entrance of the transition, the production of turbulence is higher compared to previous upstream sections. This increase in both turbulence intensities $\mathrm{u}^{`} / \mathrm{U}_{\mathrm{o}}$ and $\mathrm{v}^{`} / \mathrm{U}_{\mathrm{o}}$ occurs throughout the depth of flow. The transverse component of deflected velocity vector at the corner, interact with the longitudinal velocity vector at the centerline at the entrance, may be instrumental in higher turbulence production at $\mathrm{x} / \mathrm{b}=-1, \mathrm{x} / \mathrm{b}=0$.

Within the transition, the Reynolds and Froude numbers increased to $6.8 \times 10^{4}$ and 0.7 on average respectively. As the flow approaches critical state as indicated by $\mathrm{F}_{\mathrm{r}}$ reaching close to unity, it tends to be unstable due to higher wave disturbance, although the flow in transition is not exactly critical at $F_{r}=0.6$. In addition, oblique surface waves are seen during experimentation within the transition and few centimeters, about 30-35 cms downstream of the exit of the transition. The combined influence of these surface waves in the subcritical flow and the oblique waves due to constriction could have enhanced, the turbulence intensities in the free surface and wall region at the centre $\mathrm{x} / \mathrm{b}=0$, and beyond up to exit section at $\mathrm{x} / \mathrm{b}=1$. This surface wave disturbance effect appears predominant from the centre and at all subsequent section downstream. At the center itself at $\mathrm{x} / \mathrm{b}=0$, however, in the core region turbulence is minimum. This may be attributed to the high linear velocity generated due to constriction and reduced depth. Along the centerline defined by $\mathrm{x} / \mathrm{b}=0, \mathrm{z} / \mathrm{b}=0$; 
$\mathrm{x} / \mathrm{b}=1, \mathrm{z} / \mathrm{b}=0$; and $\mathrm{x} / \mathrm{b}=2, \mathrm{z} / \mathrm{b}=0$, the trend variation of both $\mathrm{u}^{`} / \mathrm{U}_{\mathrm{o}}$ and $\mathrm{v}^{\prime} / \mathrm{U}_{\mathrm{o}}$ is quite similar as stated earlier, viz., turbulence decreases from large magnitude in wall region reaching minimum in the core region and again rises to a large value in the free surface region. Within the core region turbulence decreases slightly as one approach the centre. At the centre itself the turbulence in the core region attains a minimum value. Continuing from the centre downstream up to the exit of transition, turbulence profile show a distinct change. Compared to the turbulence at the centre, the turbulence intensities increase in the magnitude in the core region. The turbulence variation, both in the wall region and the free surface region at the centre and up to exit section of the transition, at $\mathrm{x} / \mathrm{b}=0$ and 1 , are specifically noteworthy. Turbulence levels are enhanced significantly in the free surface and the wall regions compared to the core region. The streamwise component $u^{\prime} / \mathrm{U}_{\mathrm{o}}$ is much larger at the surface in comparison with $\mathrm{v}^{\prime} / \mathrm{U}_{\mathrm{o}}$ at the centre and exit.

Downstream of the transition in the expansions zones, Froude's number increases slightly after inlet of expansion zone and then decreases slightly, Reynolds number remains almost same at $4 \times 10^{4}$. The conditions of the flow at the inlet of the expansions zones cause unidirectional distortion of the fluid elements which may be expected to produce high nonhomogeneous and anisotropic turbulence downstream of the transition. Under the action of dynamic process, the turbulence is produced to some degree all over the field. A high level of turbulence intensities $u^{`} / U_{o}$ and $v^{`} / U_{o}$ in all expansion zone occurs compared to the upstream sections as seen in the Figure 10. Specially the maximum turbulence intensities $\mathrm{u}^{`} / \mathrm{U}_{\mathrm{o}}$ and $\mathrm{v}^{`} / \mathrm{U}_{\mathrm{o}}$ can be seen to occur either close to the free surface of close to the bed. Even in his region, turbulence intensities $\mathrm{u}^{\prime} / \mathrm{U}_{\mathrm{o}}$ and $\mathrm{v}^{`} / \mathrm{U}_{\mathrm{o}}$ in core region are relatively low. It can be 2 to 4 times as high compared to minimum value in the wall or free surface region. The nature of variation in turbulence intensities $\mathrm{u}^{\prime} / \mathrm{U}_{\mathrm{o}}$ and $\mathrm{v}^{\mathrm{\prime}} / \mathrm{U}_{\mathrm{o}}$ at the entry of expansion zone and subsequent sections downstream is somewhat distinct compared to the turbulence profiles before and within the transition. Herein, in the core region turbulence intensities profiles $\mathrm{u}^{\prime} / \mathrm{U}_{\mathrm{o}}$ and $\mathrm{v} / \mathrm{U}_{\mathrm{o}}$ do not exhibit the tendency towards constancy unlike in the transition or before the transition. Generally, after reaching the minimum turbulence intensities $u^{`} / \mathrm{U}_{\mathrm{o}}$ and $\mathrm{v}^{`} / \mathrm{U}_{\mathrm{o}}$ as the distance increases from the wall, the turbulence tends to increase consistently till the free surface is reached. Turbulence intensities are particularly largest at $\mathrm{u}^{\prime} / \mathrm{U}_{\mathrm{o}}=52 \%, \mathrm{v}^{`} / \mathrm{U}_{\mathrm{o}}=35 \%$ and $\mathrm{u}^{`} / \mathrm{U}_{\mathrm{o}}=63 \%, \mathrm{v}^{`} / \mathrm{U}_{\mathrm{o}}=40 \%$ at $\mathrm{x} / \mathrm{b}=2, \mathrm{z} / \mathrm{b}=0$ and $\mathrm{x} / \mathrm{b}=2, \mathrm{z} / \mathrm{b}=0.25$ closer to the wall region and free surface region respectively. Similarly as stated earlier both the turbulence intensities $u^{\prime} / \mathrm{U}_{\mathrm{o}}$ and $v^{`} / \mathrm{U}_{\mathrm{o}}$ are large at all the sections investigated downstream of the transition in the wall region and the free surface region. The general trend in variation of depthwise turbulence is similar in the downstream zone up to $\mathrm{x} / \mathrm{b}=5$ observed in this work. The turbulence intensities $\mathrm{u}^{\prime} / \mathrm{U}_{\mathrm{o}}$ and $\mathrm{v}^{`} / \mathrm{U}_{\mathrm{o}}$ are, however, observed to be of the same order at the wall and free surface along the centerline located at entrance to the expansion zone $\mathrm{x} / \mathrm{b}=1$, farthest section at $\mathrm{x} / \mathrm{b}=5, \mathrm{z} / \mathrm{b}=0$ and $\mathrm{x} / \mathrm{b}=5$ and $\mathrm{z} / \mathrm{b}=0.25$. However, at an intermediate location $\mathrm{x} / \mathrm{b}=2$, these values do differ significantly. The changes in turbulence intensities $\mathrm{u}^{\prime} / \mathrm{U}_{\mathrm{o}}$ and $\mathrm{v}^{\prime} / \mathrm{U}_{\mathrm{o}}$ both in the wall region and the free surface region, and noteworthy at and after the centre of transition $x / b=0$ are specifically significant. The increase in the turbulence in the downstream may be attributed to the probable separation occurrence at the exit corner and the occurrence of diverging flow, associated with the oblique surface waves.

Summing up it may be concluded that the depthwise turbulence characteristics upstream, within and downstream of the transition differ as revealed in the profiles shown. The vertical side walls may be affect the depthwise turbulence away from the transition upstream of it. However, at the entrance of the transition, at the corner, turbulence has a large magnitude particularly near the bed, but not at the centerline. Just downstream of the entrance to the transition, turbulence is significant throughout the depth for the probable role of the lateral component of velocity as explained earlier.

Free surface has a unique role in governing the turbulence in the open channel flows. Hence the effect of the free surface is emphasized in this section. As already presented, Figs.8,9 and 10 depict the variation of turbulence intensities $\mathrm{u} / \mathrm{U}_{\mathrm{o}}$ and $v^{`} / \mathrm{U}_{\mathrm{o}}$ in the channel transition at different contraction ratios, $\Delta$ $\mathrm{b} / \mathrm{b}$ of 0.3 and 0.5 , at different discharges of 15 and $40 \mathrm{Lit} / \mathrm{sec}$ at upstream, within and downstream locations. The free surface influences to a larger extent outer region. The influence of increased turbulence in the outer layer may also be transferred in the lower core region. At upstream of the transition, the most noticeable effect is the dampening streamwise and vertical components of turbulence fluctuations $\mathrm{u}^{`} / \mathrm{U}_{\mathrm{o}}$ and $\mathrm{v}^{\prime} / \mathrm{U}_{\mathrm{o}}$ near the free surface. Associated with this effect is a reduction in eddy near the free surface, as compared to the wall region(wall effect)at $y / y_{0} \leq 0.2$. Clearly, upstream of the transition, the free surface suppress the movement of eddies and the surface waves. Also, the most noticeable feature is that, Froude numbers of less than of equal 0.22 , the surface waves do not occur at the free surface. The effect of surface waves on the turbulence becomes significant when the Froude number exceeds about 0.22 as can be seen in the figures. This influence drawn from the Laser technique measurements is the same as stated by Nezu and Rodi (1986). If both the upper and lower boundaries were fixed, one would expect symmetric distribution of $\mathrm{u}^{\prime} / \mathrm{U}_{\mathrm{o}}$ and $\mathrm{v}^{`} / \mathrm{U}_{\mathrm{o}}$. The nonsymmetric turbulence distribution along the vertical with respect to the centre of the depth of channel, with larger turbulence intensities $\mathrm{u}^{\prime} / \mathrm{U}_{\mathrm{o}}$ and $\mathrm{v}^{\prime} / \mathrm{U}_{\mathrm{o}}$ at the channel bed and top of the surface, are not necessarily equal. It is concluded that, upstream of the transition, turbulence fluctuation $\mathrm{u}^{\prime} / \mathrm{U}_{\mathrm{o}}$ and $v^{`} / \mathrm{U}_{\mathrm{o}}$ are slightly decreased at the free surface as 
compared to the wall region. Within the transition, the flow approaching the critical condition from the tranquil state, Froude number close to 1.0 , the turbulence intensities $\mathrm{u}^{\prime} / \mathrm{U}_{\mathrm{o}}$ and $v^{`} / \mathrm{U}_{\mathrm{o}}$ near the free surface are higher as compared to the core region. The turbulence intensity $\mathrm{u}^{\prime} / \mathrm{U}_{\mathrm{o}}$ at the free surface is always larger than $v^{\prime} / \mathrm{U}_{\mathrm{o}}$ although both increase as the flow proceeds downstream. It may be explained by noting that, as the flow approaches near critical condition, the oblique waves under chocking state were formed within the transition. This leads to high values of velocity gradients and surface disturbances leading to the greater turbulence production. Downstream of all the transition, the probable separation and wave generation coupled with the oblique surface waves transmitted to about $30-40 \mathrm{cms}$, generates nonhomogeneous and anisotropic turbulence. This can be clearly noted, for instance, at $\Delta \mathrm{b} / \mathrm{b}=0.5$ as shown Fig. 10, the maximum turbulence intensities $\mathrm{u}^{`} / \mathrm{U}_{\mathrm{o}}$ and $\mathrm{v}^{`} / \mathrm{U}_{\mathrm{o}}$ occur at the free surface; $\mathrm{u}^{\prime} / \mathrm{U}_{\mathrm{o}}$ at the free surface being twice as large as at the wall at $\mathrm{x} / \mathrm{b}=2, \mathrm{z} / \mathrm{b}=0.25$ and also at $\mathrm{x} / \mathrm{b}=1$ and $\mathrm{z} / \mathrm{b}=0.25$.

Fig.11 depicts the profiles of streamwise mean velocity distribution $\overline{\mathrm{u}} / \mathrm{U}_{\mathrm{o}}$ of channel transition along the depth for discharge $40 \mathrm{Lit} / \mathrm{sec}$ at different locations upstream, within and downstream of the transition at free stream Reynolds and Froude numbers of $0.4 \times 10^{5}$ and 0.240 respectively. The main observations are as follow. The streamwise mean velocity profile along the longitudinal direction at the centerline of the transition indicates general increase from upstream zone up to the entrance of expansion zone of the transition. Subsequently, the magnitude decreases gradually downstream. At the corner locations of the transitions, reversed flow and flow separation could be observed downstream of the transition as show in Fig. 11 at $x / b=1$ at $z / b=0.25$ as can be seen by the shape of the velocity profile and was observed by dye injection. Reversed flow was also observed at the beginning of the transition. With the increase in the contraction $\Delta b / b$, the flow reversal also increased. On the other hand the maximum velocity occurs close to the end of the transition at the centerline $\mathrm{z} / \mathrm{b}=0, \mathrm{x} / \mathrm{b}=1$ and 2, below the free surface in the downstream zone. Velocity distribution along the depth shows a curvilinear nature, with greater distance downstream.

Fig.12 depicts the profile of vertical mean velocity $\bar{v} / \mathrm{U}_{\mathrm{o}}$ profiles is marked changes in the magnitude along the depth. In $\overline{\mathrm{u}} / \mathrm{U}_{\mathrm{o}}$ profile, changes were relatively smooth, with smaller number of points of contraflexure in wall, core and the free surface regions. Secondly, $\bar{v} / \mathrm{U}_{\mathrm{o}}$, assumes both positive and negative values at the same section and hence the zero value also at some intermediate locations. This nature of variation, viz., change from positive to negative magnitude and viceversa occurred almost at all the sections. However, in the profile of $\overline{\mathrm{u}} / \mathrm{U}_{\mathrm{o}}$ such a variation occurred near the separation zone due to reversal of flow. Thirdly, the zero magnitude of vertical velocity component $\bar{v} / U_{o}$ occurs at more than one point at several locations. This observations is somewhat more intriguing as one may not expect more than one location at which $\overline{\mathrm{v}} / \mathrm{U}_{\mathrm{o}}$ could be zero. Fourthly, the magnitude $\overline{\mathrm{v}} / \mathrm{U}_{\mathrm{o}}$ of increases steadily from the upstream section from relatively a small value (albeit predominantly negative in the farthest section of this investigation) with a gradual increase reaching maximum positive and negative values at the centre of the transition, $\mathrm{x} / \mathrm{b}=0$ and $\mathrm{z} / \mathrm{b}=0$. At exact entrance location, velocity $\overline{\mathrm{V}} / \mathrm{U}_{\mathrm{o}}$ is negative all along the vertical height. At $\mathrm{x} / \mathrm{b}=1, \mathrm{z} / \mathrm{b}=0.25$ just outside the exit section of transition, velocity $\overline{\mathrm{V}} / \mathrm{U}_{\mathrm{o}}$ is positive and a fairly of large magnitude. Subsequently, although $\bar{v} / \mathrm{U}_{\mathrm{o}}$ fluctuates as one moves downstream of the transition, the magnitude gradually decreases reaching relatively small value again at the farthest downstream of $\mathrm{x} / \mathrm{b}=5$.

In order to study turbulences variation downstream of the compound transition covering the entire cross section and longitudinal direction, the turbulence intensities $\mathrm{u} / \mathrm{U}_{\mathrm{o}}$ and $\mathrm{v}^{`} / \mathrm{U}_{\mathrm{o}}$ were measured at three transverse locations $\mathrm{z} / \mathrm{b}=0.0,015$ and 0.30 , and several longitudinal $\mathrm{x} / \mathrm{b}$ locations, in $\mathrm{a}$ horizontal plane $y / y_{0}=0.5$ for three contraction ratios of $\Delta \mathrm{b} / \mathrm{b}=0.5$ and 0.3 , for $\mathrm{Q}=45 \mathrm{lit} / \mathrm{s}$. Figs. 13 and 14 depict these variation of turbulence intensities $u^{\prime} / \mathrm{U}_{\mathrm{o}}$ and $\mathrm{v}^{\prime} / \mathrm{U}_{\mathrm{o}}$. The trend of variation in both streamwise and vertical turbulence intensities is quite similar, the maxima of both the intensities also occurring at the same location of $\mathrm{x} / \mathrm{b}$. A slight shift in $\mathrm{x} / \mathrm{b}$ for such a maxima was sometimes noticed. The turbulence rises rapidly to reach maxima in the of $3<x / b<4.5$. In the region beyond $\mathrm{x} / \mathrm{b}>4.5$, turbulence decreases smoothly and continuously at slower rate for all the cases. For $\mathrm{z} / \mathrm{b}=0$ and 0.15 , the trend is reverse at $3<\mathrm{x} / \mathrm{b}<4.5$ in all the cases. It is noted that the steamwise turbulence $\mathrm{u}^{\prime} / \mathrm{U}_{\mathrm{o}}$ is stronger compared to the vertical turbulence $v^{`} / \mathrm{U}_{\mathrm{o}}$. In the inlet region of the expansion (transition outlet), the turbulence increases as the side wall is approached as noted earlier. For $z / b$ of 0.3 the turbulence levels are higher along the length of the channel. The nature of variance of turbulence in all the cases clearly indicate that the flow is nonisotropic and nonhomogeneous at all locations. As well as later, isotropy of turbulence has been observed at some locations and depths. Although the nature of variation in turbulence $\mathrm{u}^{\prime} / \mathrm{U}_{\mathrm{o}}$ and $\mathrm{v} / \mathrm{U}_{\mathrm{o}}$ are similar in all the cases, the difference in magnitude of the variation in turbulence for $\Delta \mathrm{b} / \mathrm{b}=0.5$ and 0.3 , and also at the location $\mathrm{z} / \mathrm{b}=0.3$ is significant.

Figs.15 and 16 show the variation of turbulence intensities $\mathrm{u}^{\prime} / \mathrm{U}_{\mathrm{o}}$ and $\mathrm{v}^{\prime} / \mathrm{U}_{\mathrm{o}}$ at $\mathrm{y} / \mathrm{y}_{\mathrm{o}}$ of 0.5 downstream of compound transition in the expansion zones beyond $\mathrm{x} / \mathrm{b}=0$ at three spanwise locations $\mathrm{z} / \mathrm{b}$ of 0 and 0.25 for $\mathrm{Q}=45 \mathrm{lit} / \mathrm{sec}$ at different $\Delta \mathrm{b} / \mathrm{b}$ of $0.5,0.4$ and 0.3 . Both the $\mathrm{u}^{`} / \mathrm{U}_{\mathrm{o}}$ and $\mathrm{v}^{`} / \mathrm{U}_{\mathrm{o}}$ increased rapidly and almost simultaneously. Rate of increase of turbulence is greater than the rate of decrease after reaching the maximum, in all the cases. A slight gradual increase in $\mathrm{x} / \mathrm{b}$ at which the $u^{`} / \mathrm{U}_{\mathrm{o}}$ and $\mathrm{v}^{`} / \mathrm{U}_{\mathrm{o}}$ are maximum, is observed as the contraction ratio $\Delta \mathrm{b} / \mathrm{b}$ decreases from 0.5 to 0.3 , in all the 
cases of experimentation. The maximum turbulence occurs for the maximum $\Delta \mathrm{b} / \mathrm{b}$ ratio, viz 0.5 in the present investigation and the least of the maximum turbulence occurs for minimum $\Delta \mathrm{b} / \mathrm{b}$ of 0.30 . Similarly, the largest maximum turbulence intensities $u^{`} / \mathrm{U}_{\mathrm{o}}$ and $v^{`} / \mathrm{U}_{\mathrm{o}}$ occur at spanwise location $\mathrm{z} / \mathrm{b}=0.25$ and smallest of the maximum turbulence intensity occur at spanwise location $\mathrm{z} / \mathrm{b}=0$. At $\mathrm{z} / \mathrm{b}=0$ i.e. at the centerline turbulence intensities $\mathrm{u}^{`} / \mathrm{U}_{\mathrm{o}}$ and $\mathrm{v}^{`} / \mathrm{U}_{\mathrm{o}}$ assume intermediate values. Turbulence intensities at the wall itself will be nil. Thus the turbulence intensities in transverse direction decrease form the maximum approximately at $\mathrm{z} / \mathrm{b}=0.25$ and fall again to zero at the wall. The trend is the same in all the cases of experimental observation.

\section{CONCLUSIONS}

The conclusions arising out of this study can be summarizes as follows:

The relative protection length $\mathrm{L} / \mathrm{b}$ increases with the increase of the incoming Froude number $F_{u}$ at particular contraction ratio $\Delta b / b$ and fixed bottom slope $S_{0}$. Also, the $L / b$ increase with the increase of the bottom slope. The flatter the bottom slope $S_{0}$ is, the shorter the relative protection length, at particular lateral contraction ratio and certain value of upstream Froude number. The L/b increases with the increase of lateral contraction ratio $\Delta \mathrm{b} / \mathrm{b}$. The smaller the contraction ratio, the smaller the relative protection length, at particular bottom slope. At particular bottom slope and lateral contraction ratio, the relative protection length $\mathrm{L} / \mathrm{b}$ as the vertical transition ratio $\mathrm{h} / \mathrm{b}$ increases for particular upstream Froude number.

Free surface has a unique role in governing the turbulence in the open channel flow. The free surface influences to a larger extent outer region. The influence of increased turbulence in the outer layer may also be transferred in the lower core region. At upstream of the transitions, the most noticeable effect is the dampening of turbulence intensities near the free surface, Associate with this effect is a reduction in eddy viscosity near the free surface, as compared to the wall region (wall effect), also the free surface suppresses the movement of eddies and the surface waves in the upstream of the transition. An increase in the Froude and Reynolds numbers, decreases the streamwise ad vertical turbulence intensities upstream slightly, followed by slight increase in the turbulence intensities downstream of the transition in the expansion zone at the same flow condition. This effect in the turbulence occurs primarily in the wall region and the free surface region. However, in the core region no noticeable change in the turbulence levels upstream, within and downstream regions of the transition occurs. Within the transition, flow tends towards the critical state $\left(F_{r}\right.$ approaches close to 1$)$ with a rise in the turbulence intensities $\mathrm{u}^{\prime} / \mathrm{U}_{\mathrm{o}}$ and $\mathrm{v}^{\prime} / \mathrm{U}_{\mathrm{o}}$ in the free surface and the wall region which may be attributed to the flow tending towards critical state. At small values of Froude number $F_{r} \leq 0.22$, the effect of $F_{r}$ on turbulence intensities $u / / U_{o}$ and $\mathrm{v}^{`} / \mathrm{U}_{\mathrm{o}}$ and the free surface wave is negligible. As a comprehensive observation, it is noted that, the stream wise turbulence $u^{\prime} / \mathrm{U}_{\mathrm{o}}$ is always greater to the vertical turbulence $v^{`} / \mathrm{U}_{\mathrm{o}}$. The turbulence intensities $\mathrm{u}^{\prime} / \mathrm{U}_{\mathrm{o}}$ and $\mathrm{v}^{\prime} / \mathrm{U}_{\mathrm{o}}$ are higher nearer the bed in the wall region defined by $y / y_{0} \leq 0.2$ due to wall effect and the free surface region defined by $y / y \geq 0.6$ due to free surface effect. In the intermediate core region defined by $0.2<y / y_{0}<0.6$, minimum turbulence intensities $u / U_{o}$ and $v^{`} / \mathrm{U}_{\mathrm{o}}$ occur. With the increasing channel contraction, the variation of turbulence intensities $u^{\prime} / U_{o}$ and $v^{`} / U_{o}$ increase and become pronounced within and downstream of the transition, changing rapidly in the wall, core and the free surface regions

\section{NOMENCLATURE}

b Channel width,

$\Delta$ b Channel contraction,

$F_{u}$ Upstream Froude number,

$\mathrm{R}_{\mathrm{e}}$ Reynolds number,

L Protection length, spacing between(2)and(3),

$\mathrm{L}_{\mathrm{t}}$ Transition length (length of contracted reach)

$\mathrm{U}_{\mathrm{o}}$ Streamwise mean free steam, velocity averaged over the cross section.

$\mathrm{u}^{`}$ Streamwise turbulence intensity component in $\mathrm{x}$-direction (RMS)

$\overline{\mathrm{u}}$ Streamwise mean velocity component in $\mathrm{x}$ - direction

(RMS) Root mean square

V` Vertical turbulence intensity component in $\mathrm{y}$ - direction (RMS).

$\bar{v}$ Vertical mean velocity component in y- direction.

$\mathrm{x}$ Longitudinal axis along channel length

y Transverse axis along channel height

$\mathrm{y}_{\mathrm{o}}$ Free stream water depth

$\mathrm{y}_{\mathrm{u}}$ Upstream water depth

$\mathrm{z}$ Lateral axis along channel width

$h$ Height of vertical transition

$\mathrm{S}_{\mathrm{o}}$ Bottom slope.

Q Flow discharge

\section{REFERENCES:}

[1] Antonia, R.A., and Rajagoplala, S. (1982), "Reynolds Number Dependence of the Structure of a Turbulent Boundary Layer", Prof. J. Fluid Mechanics, 121: Pp. 121-140.

[2] Chen, C., and Jaw, S. (1997), "Fundamentals of Turbulence Modeling", Teylor \& Francis, London.

[3] Clauser, F. (1956), "The Turbulent Boundary Layer", Adv. Appl Mech., 4, 1-51.

[4] Dancey, C.H. (1990), "Measurement of Second order Turbulence statistics in an Axial Flow Compressor via 3-Component LDA”, AIAA J., 90, 2017.

[5] Ead, S., Rayaratnam, N., Katopodis, C., Ade, F. (2000), "Turbulent Open Channel Flow in Circular corrugated Culverts", J. Hydraul. Eng., 126 (10), 750 - 757. 
[6] Hitoshi, S., Akiyama, M., Mitsunobu, F.O., and Sato, T. (1995), "Numerical Analysis of Developing Turbulent Flow in a Square sectioned 90 degree bend". Trans. Jpn. Soc. Mech. Eng., Ser. B, 61 (587), 23932400.

[7] Kim, J., Kline, S., Johnston, J.P. (1980), "Investigation of a Reattaching Turbulent Shear Layer; Flow over a Backward Faing Step”. J. Fluids Eng., 102, 302.

[8] Kironoto, B.A., and Graf, W. H. (1994), "Turbulence Characteristics in Rough Uniform Open Channel Flow", Proc., Inst. Civ. Eng., Waters, Maritime Energy., 98.

[9] Kline, S. J., Reynolds, W.C., Schraub, F.A., and Runstadler, P.W. (1967), "The Structure of Turbulent Boundary Layer. "J. Fluid Mech., 30, 741-773.

[10] MeLelland, S., Asworth, P., Best, J., and Livesey, J. (1999), "Turbulence and Secondary Flow over Sediment Stripes in Weakly Bimodal Bed Matevial", J. Secondary Flows, 125 (5), 463-473.
[11] Mehta, P.R. (1981), "Separated Flow Through Large Sudden Expansions", J. Hydraaul. Div., Am. Soc. Civ. Eng., 107 (4), 451-460.

[12] Nezu, J., and Nakagawa, H. (1993), "Turbulence in Open Channel Flows", A. A. Balkema, Rotterdam, The Netherlands.

[13] Nakagawa, H., and Nezu, I.,(1987)"Experimental Investigation on Turbulent Structure of Back facing Step Flow in an Open Channel", J. Hydraulic Research, IAHR, 25, Pp. 67-88.

[14] Nezu, I., and Rodi, W.,(1993)“Open Channel Flow Measurements with a Laser Doppler Velocimetry", J. Hydraulic Engg., ASCE, 112, Pp. 335-355, 1986.

[15] Nezu, I., and Nakagawa, H., "Turbulence in Open Channel Flows", IAHR-Mongraph, A.A. Balkema Publishers, Old Post Road, Brookfield, VT 05036,USA.

[16] Rodi, W.,(1994)“Turbulence Models and their Application in Hydraulics", IAHR Monograph, A.A. Balkema Publishers, Old Post Road, Bookfiels, VT 05036, USA. 


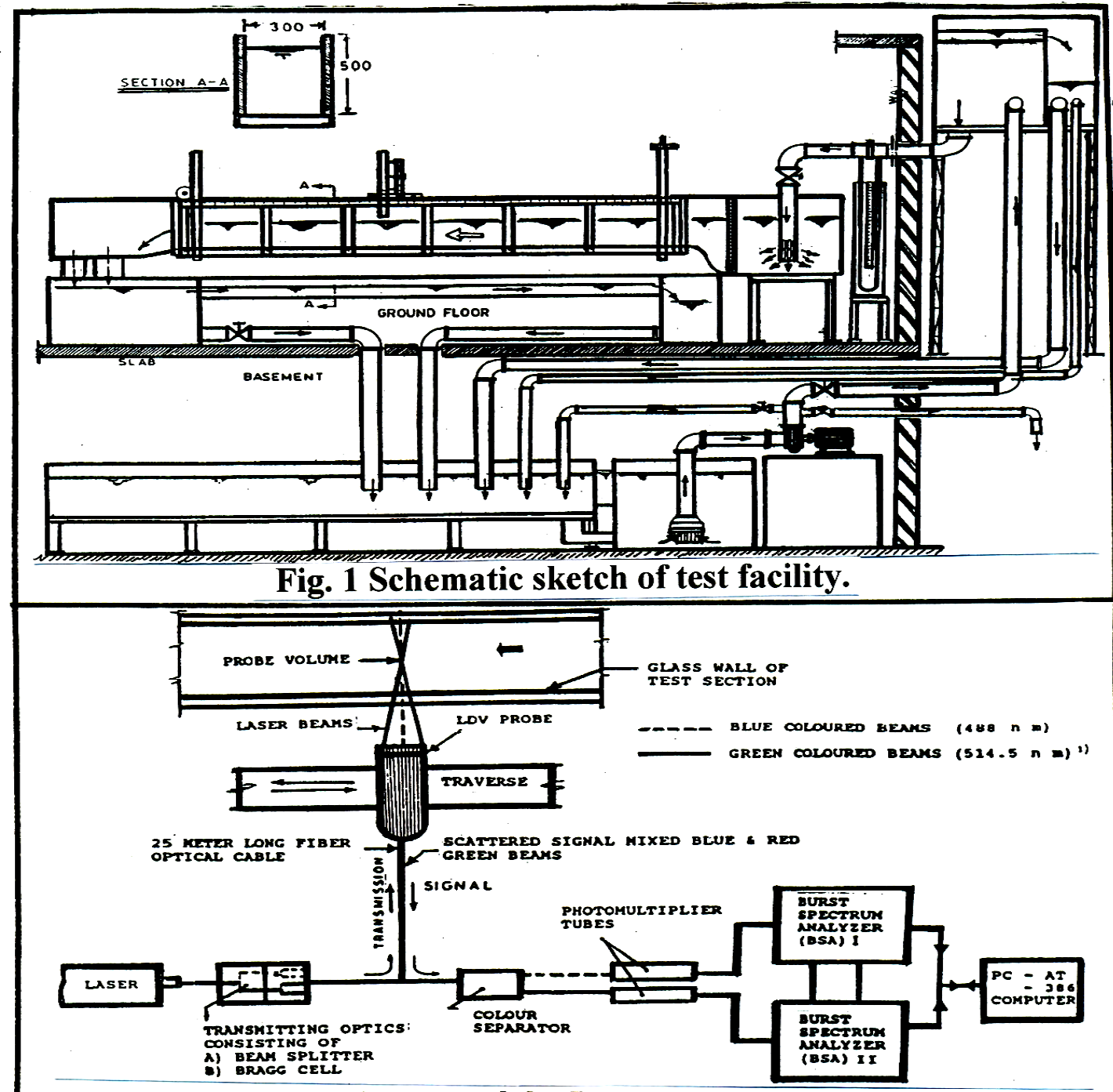

Fig. 2 Block diagram of the Laser Doppler Velocimetry.

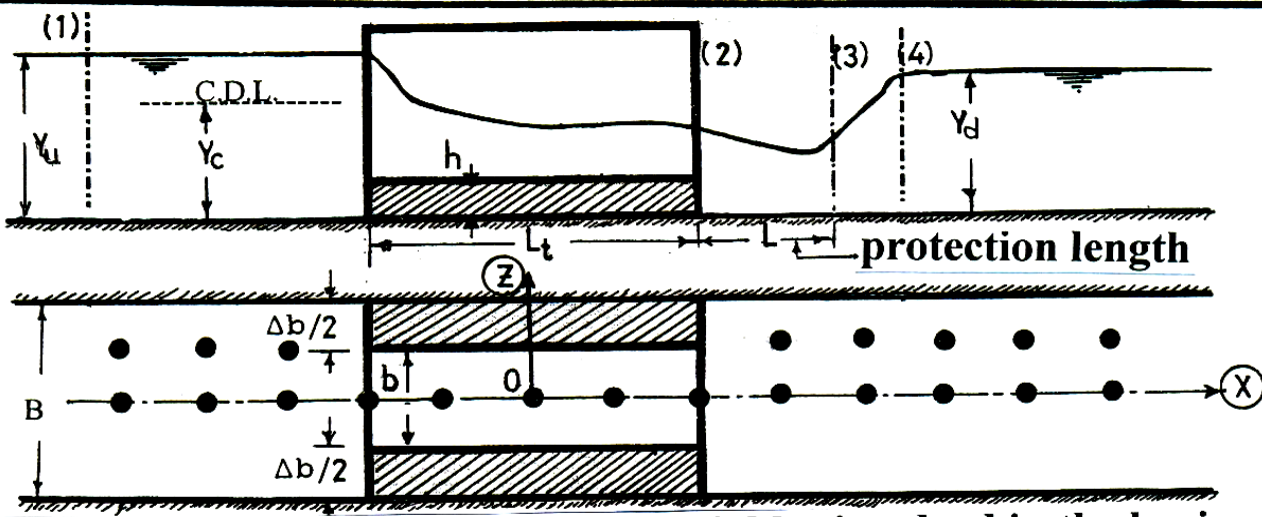

Fig. 3 Definition sketch showing the variables involved in the horizontal and vertical contraction in sloping channel in the present study. 


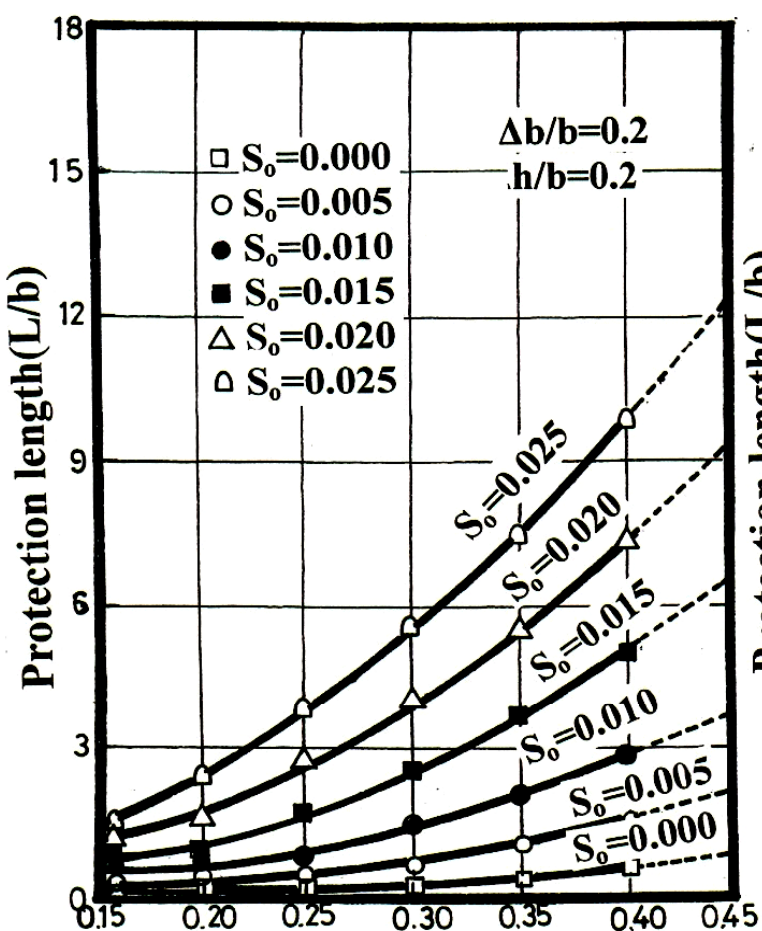

Upstream Froude number $\left(F_{u}\right)$

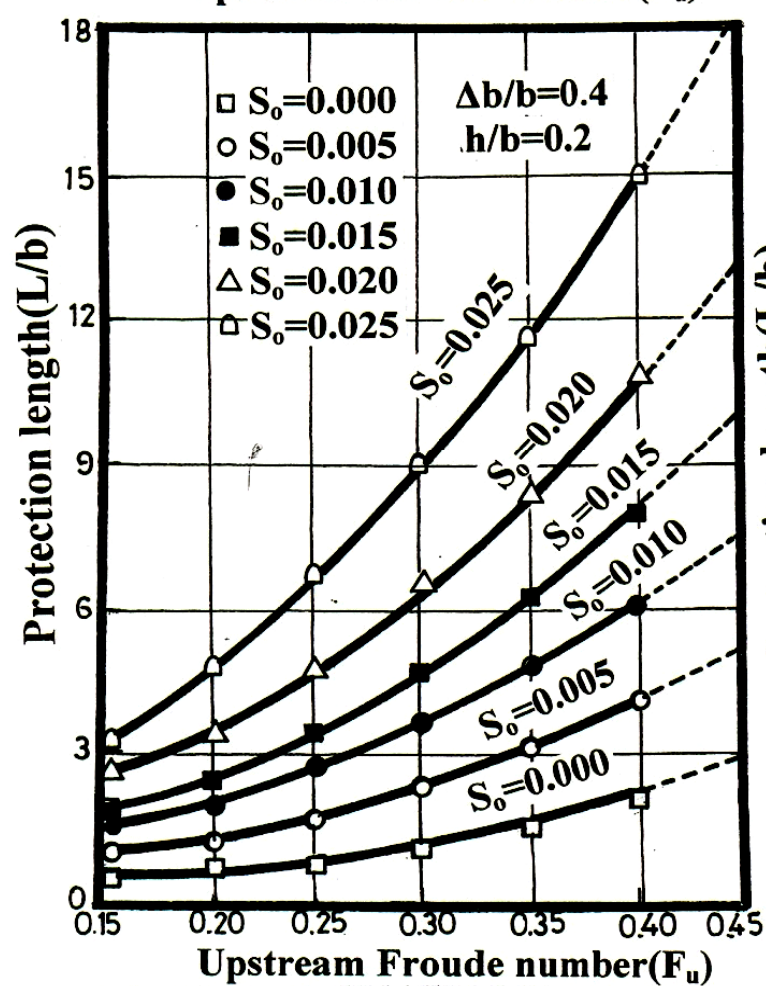

Fig.(4)Variation of upstream Froude number $F_{u}$ with protection length

$L / b$ for different bed slope $S_{0}$ at different contraction ratios $\Delta b / b$ at fixed relative height $h / b=0.2$
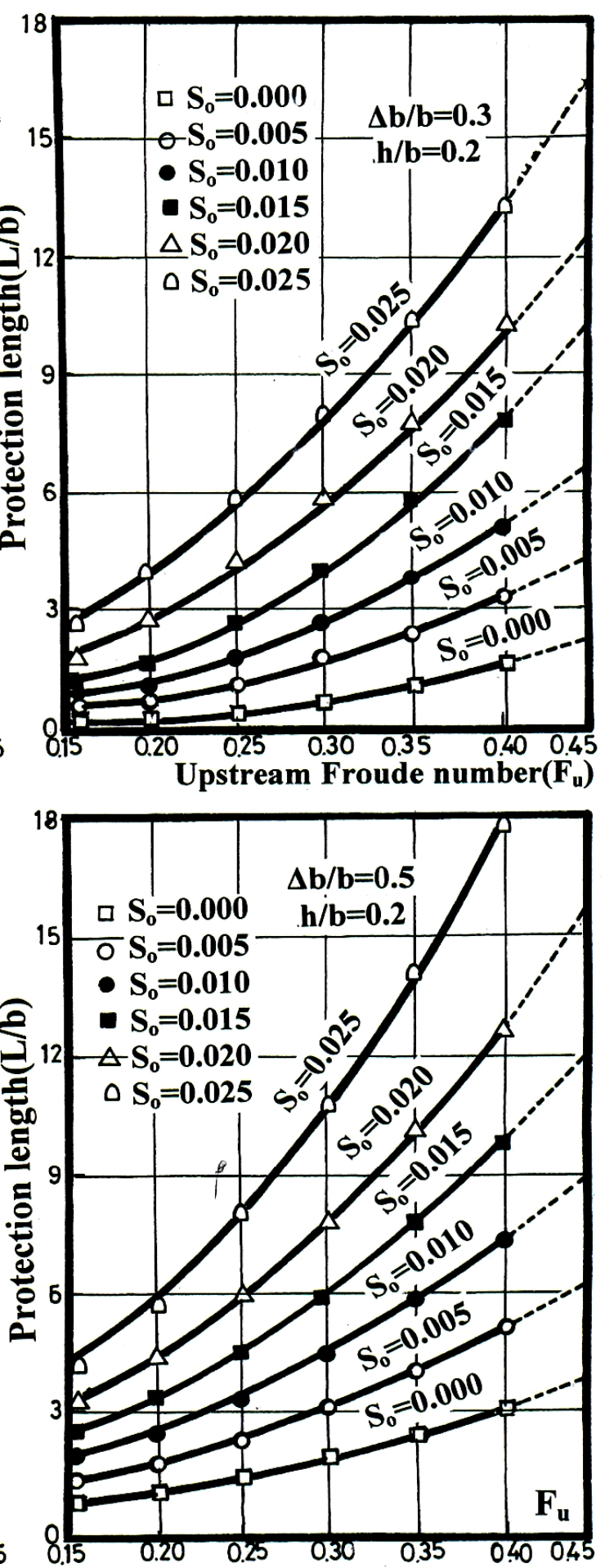

Upstream Froude number $\left(F_{u}\right)$ 

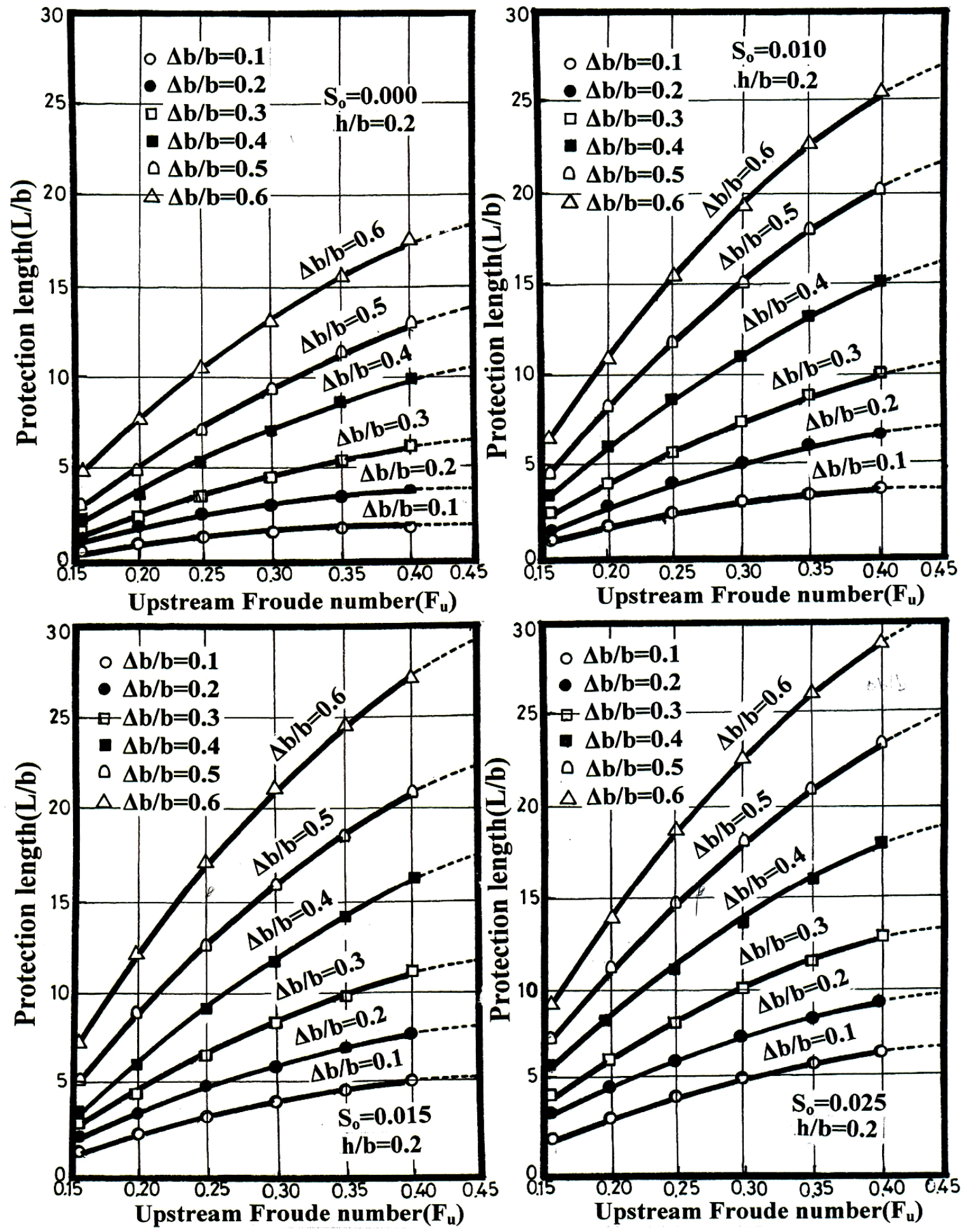

Fig.(5)Variation of upstream Froude number $F_{u}$ with protection length $L / b$ for different contraction ratios $\Delta b / b$ at different bed slope $S_{0}$ at fixed relative height $h / b=0.2$. 

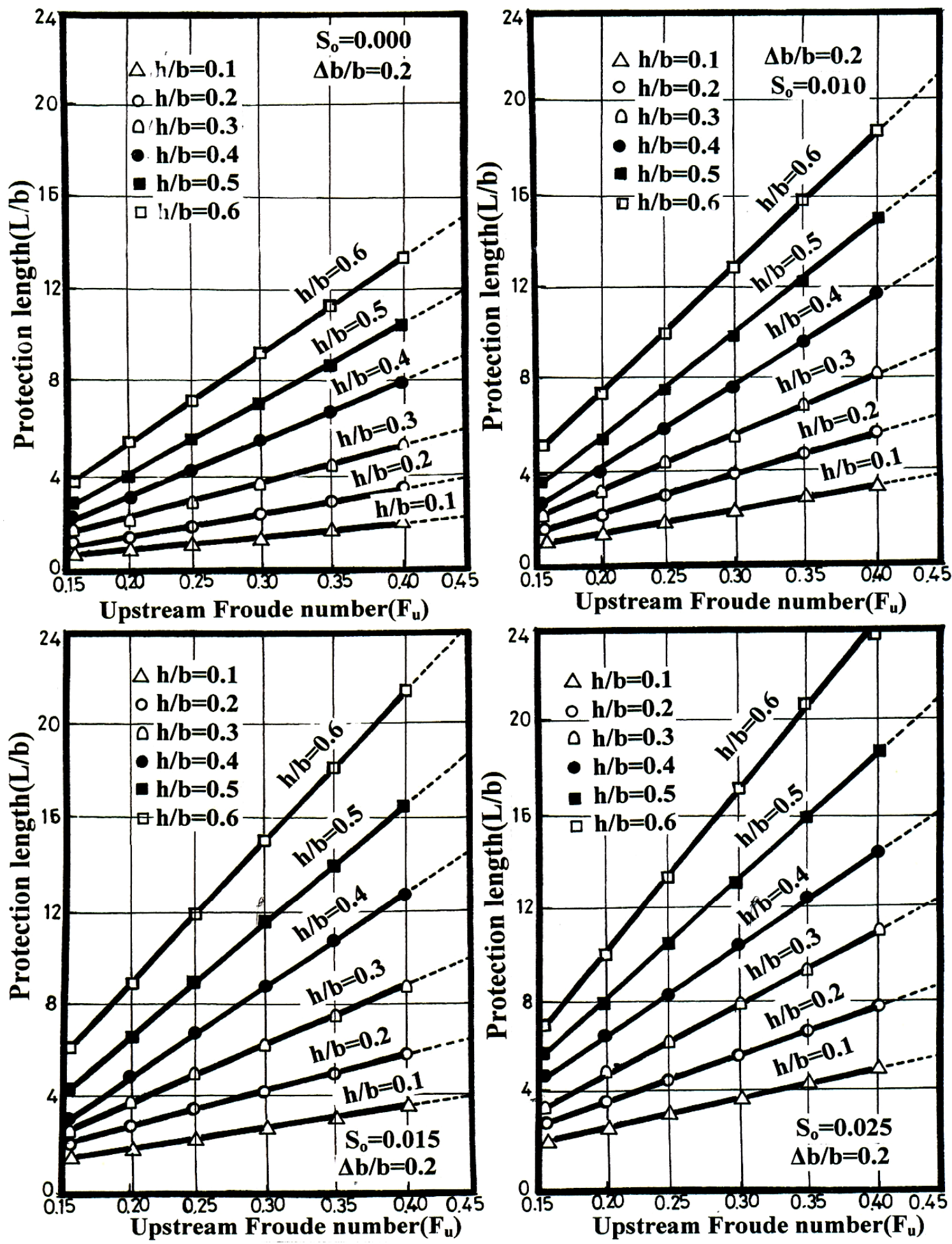

Fig.(6)Variation of upstream Froude number $F_{u}$ with protection length $\mathrm{L} / \mathrm{b}$ for different relative height $\mathrm{h} / \mathrm{b}$ at different bed slope $S_{0}$ at at fixed contraction ratio $\Delta b / b=0.2$. 

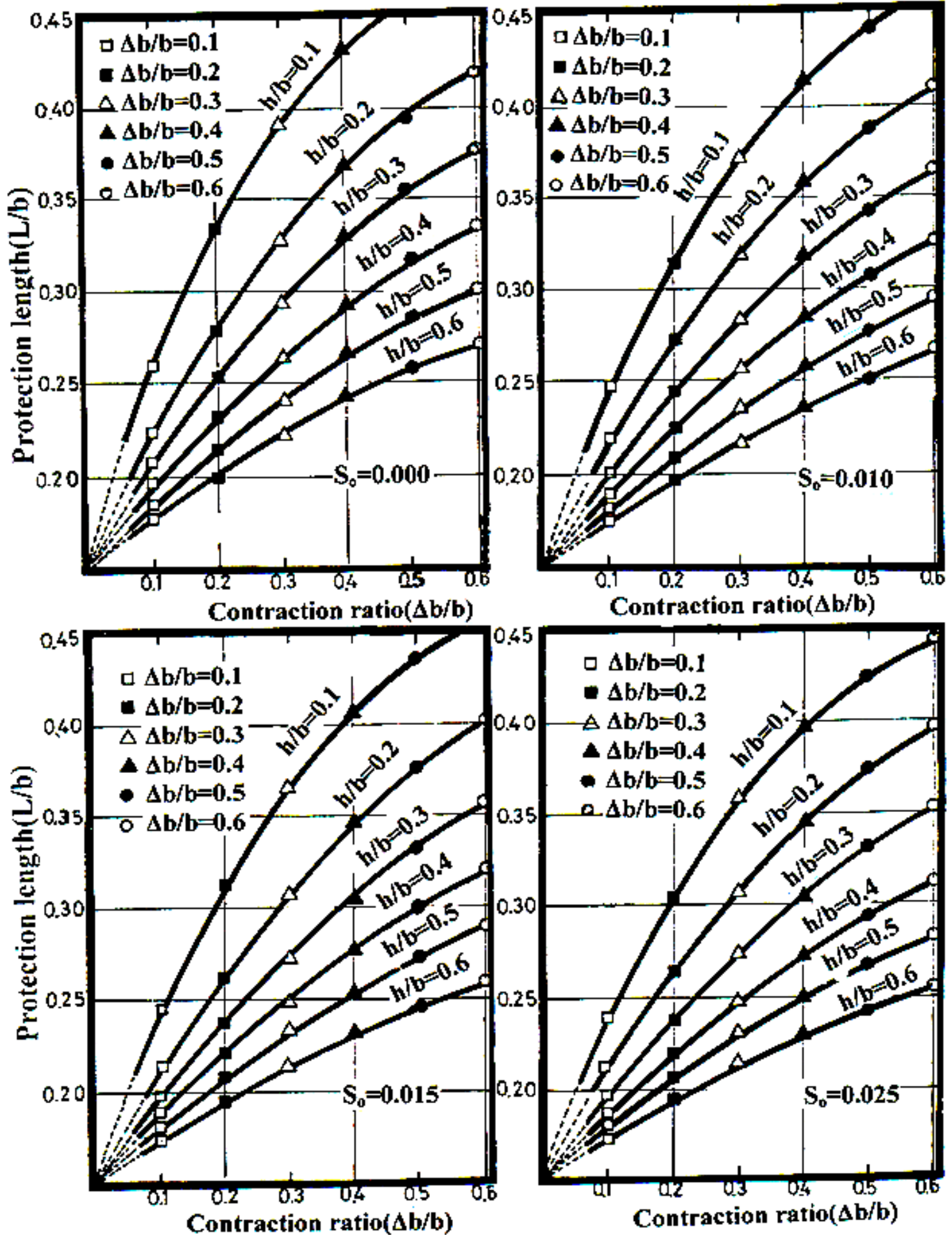

Fig.(7)Variation of contraction ratio $\Delta \mathrm{b} / \mathrm{b}$ with Protection length $(L / b)$ for different relative height $h / b$ at different bed slope 

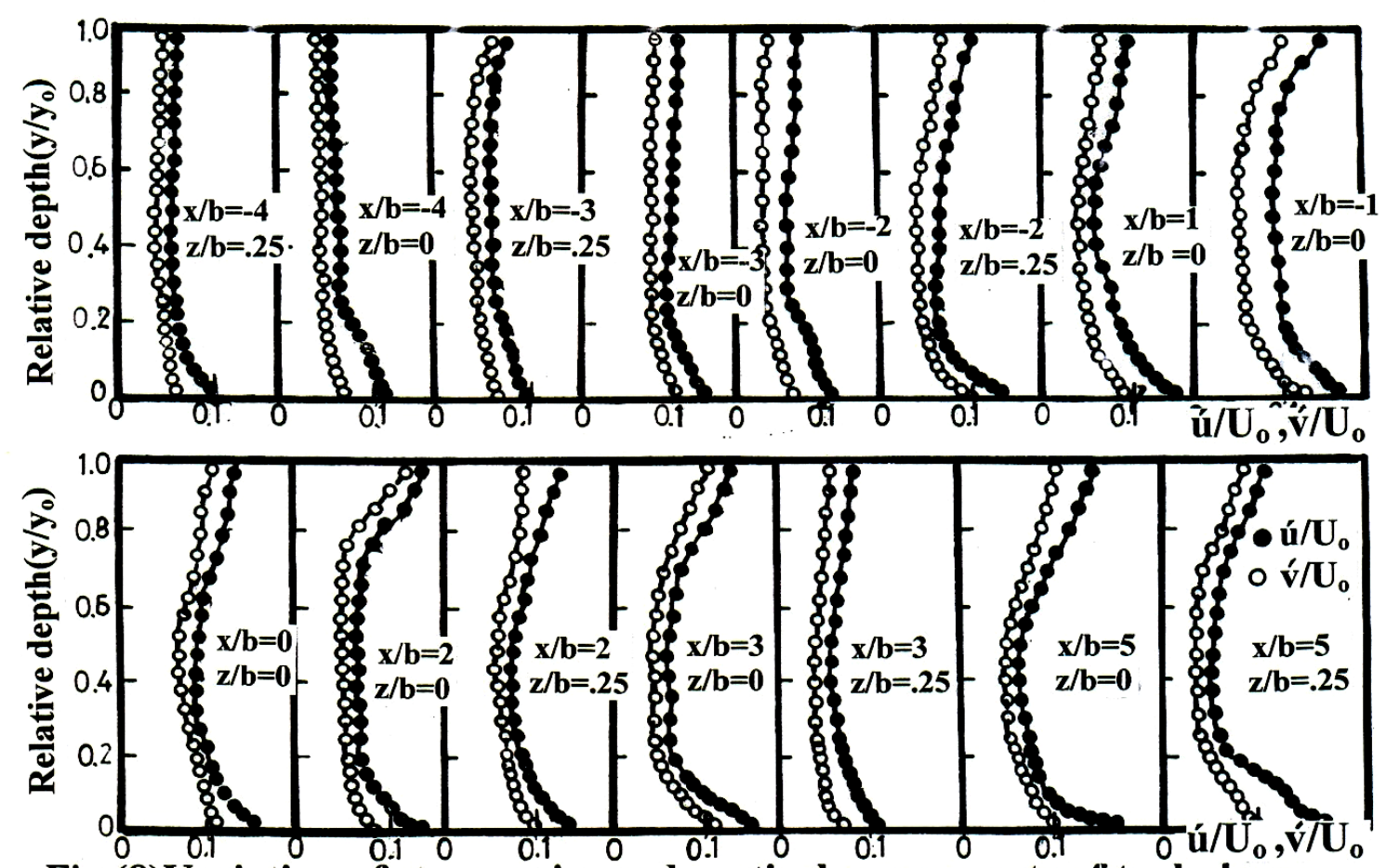

Fig.(8)Variation of streamwise and vertical components of turbulence intensities $u ́ / U_{0}$ and $v / U_{0}$ with relative water depth $y / y_{0}$ at different
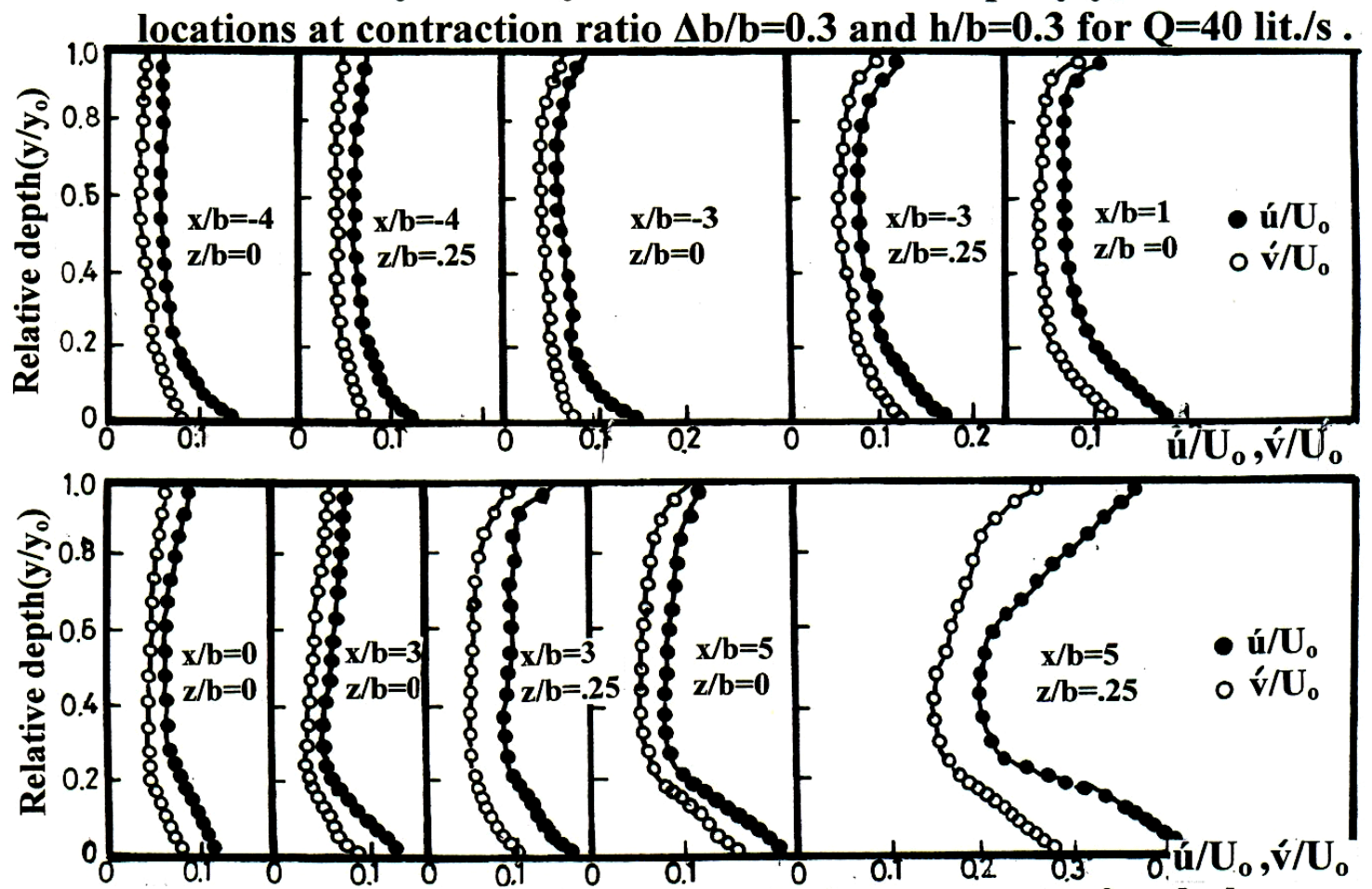

Fig.(9)Variation of streamwise and vertical components of turbulence intensities $u / U_{0}$ and $v / U_{0}$ with relative water depth $y / y_{0}$ at different locations at $\Delta b / b=0.3$ and relative height $h / b=0.3$ for $Q=15$ lit./s. 

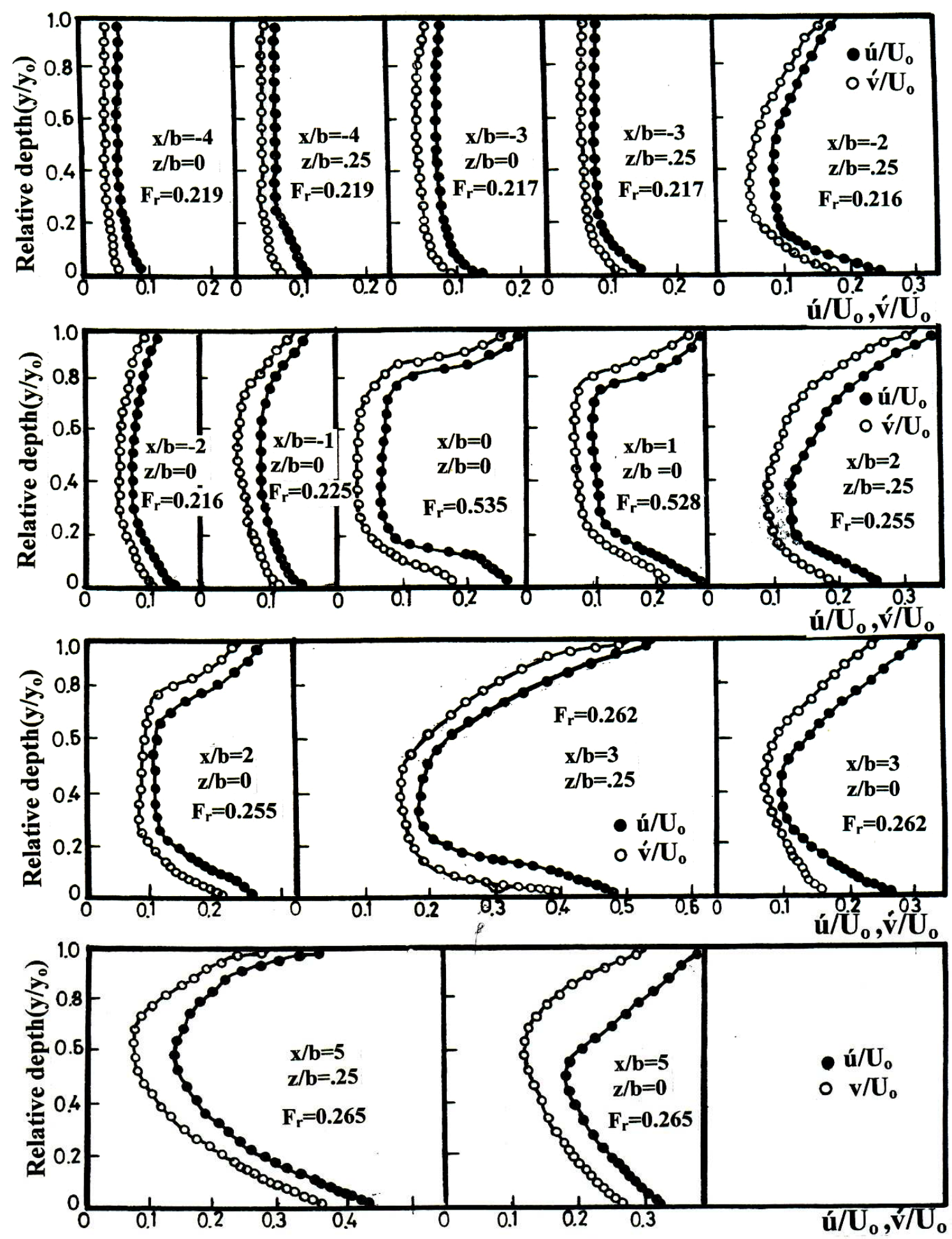

Fig.(10)Variation of streamwise and vertical components of turbulence intensities $\mathbf{u} / \mathrm{U}_{0}$ and $\dot{v} / \mathrm{U}_{0}$ with relative water depth $\mathbf{y} / \mathbf{y}_{0}$ at different locations at $\Delta b / b=0.5$ and $h / b=0.3$ for $Q=40$ lit./s . 

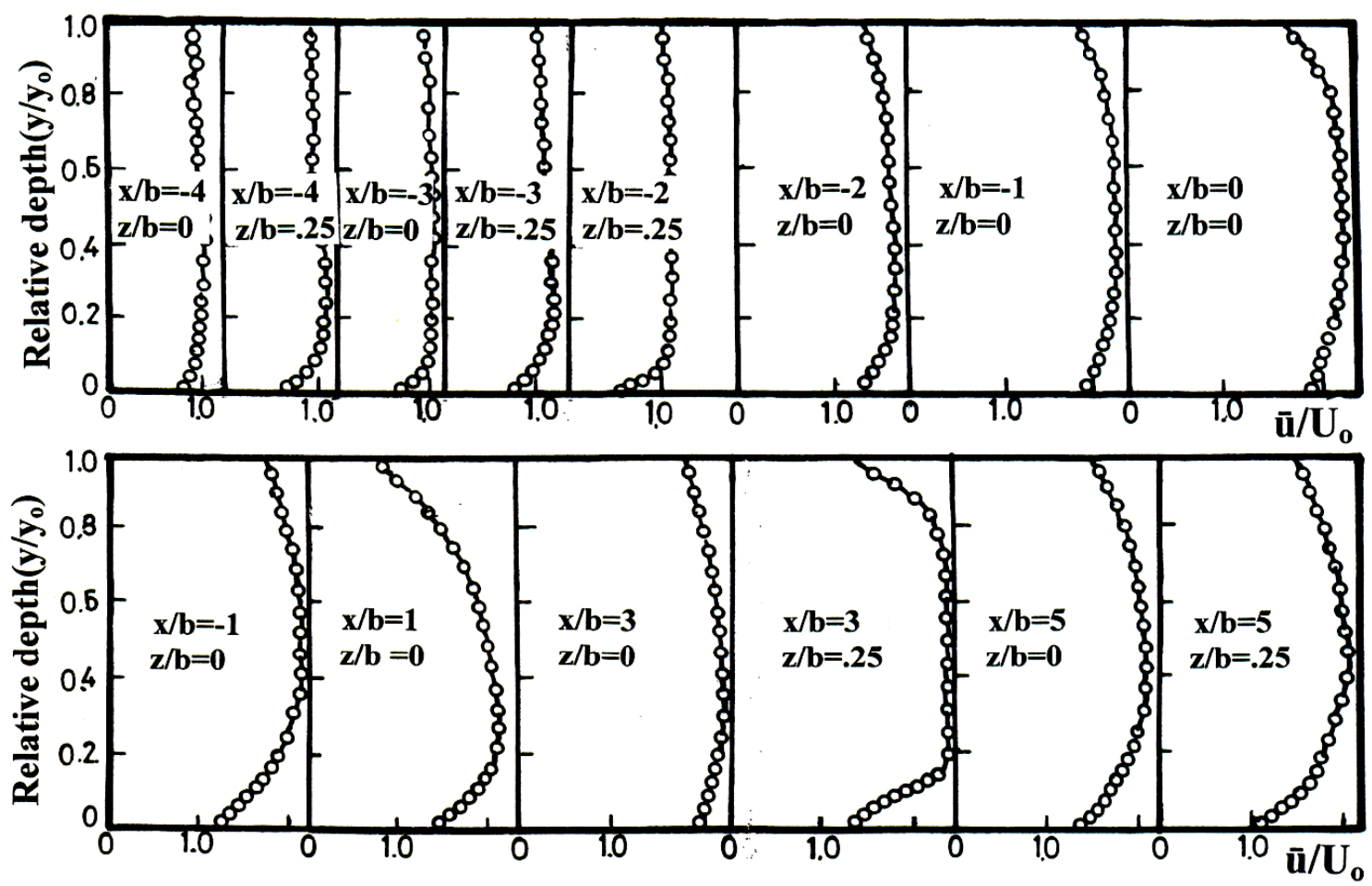

Fig.(11)Distribution of streamwise mean velocity component $\overline{\mathbf{u}} / \mathrm{U}_{0}$ over the depth at different locations at $\Delta b / b=0.5$ and $h / b=0.3$ for $Q=40$ lit./s.
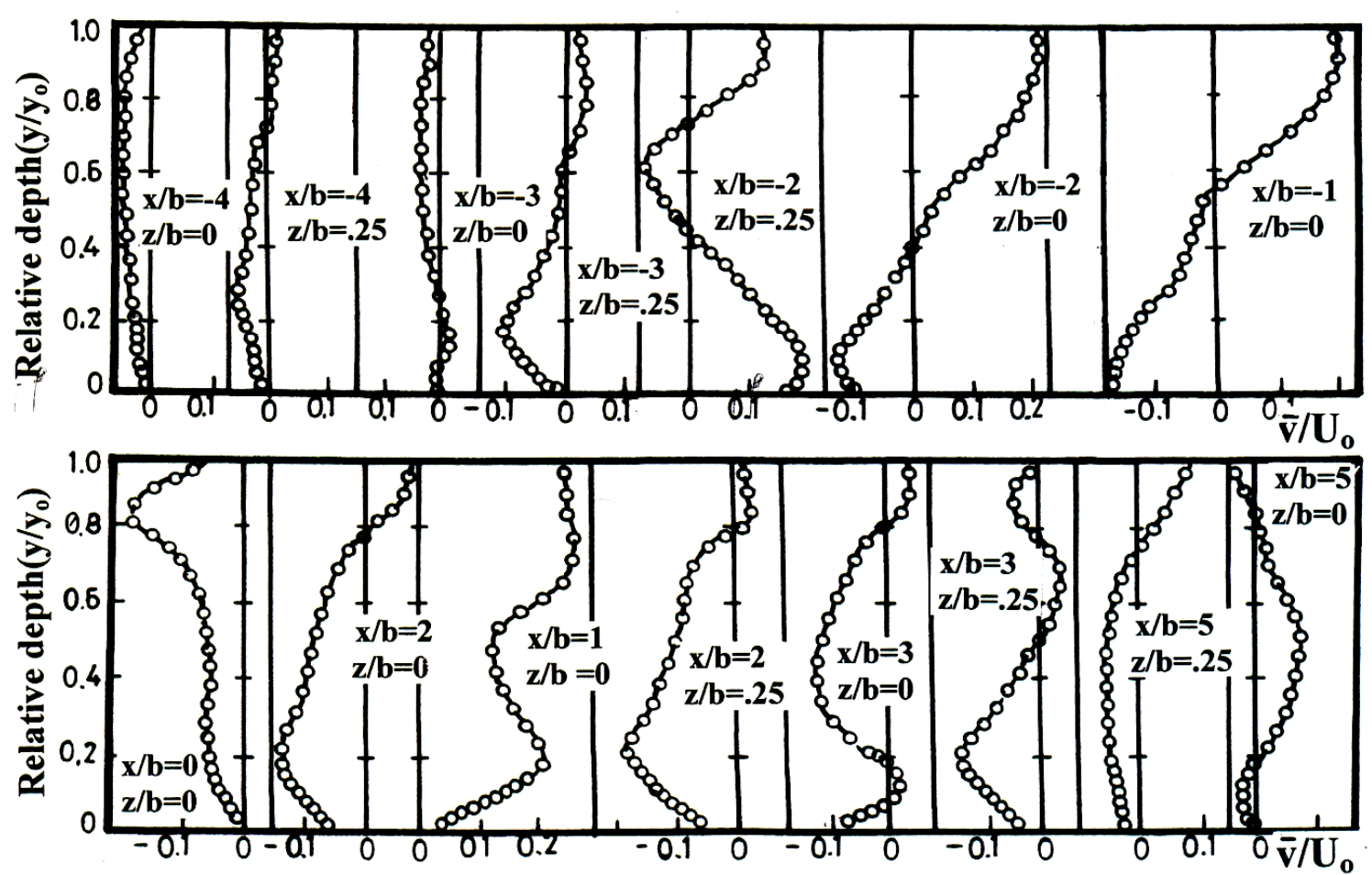

Fig.(12)Distribution of vertical mean velocity component $\bar{v} / U_{0}$ over the depth at different locations at $\Delta b / b=0.5$ and $h / b=0.3$ for $Q=40$ lit./s. 


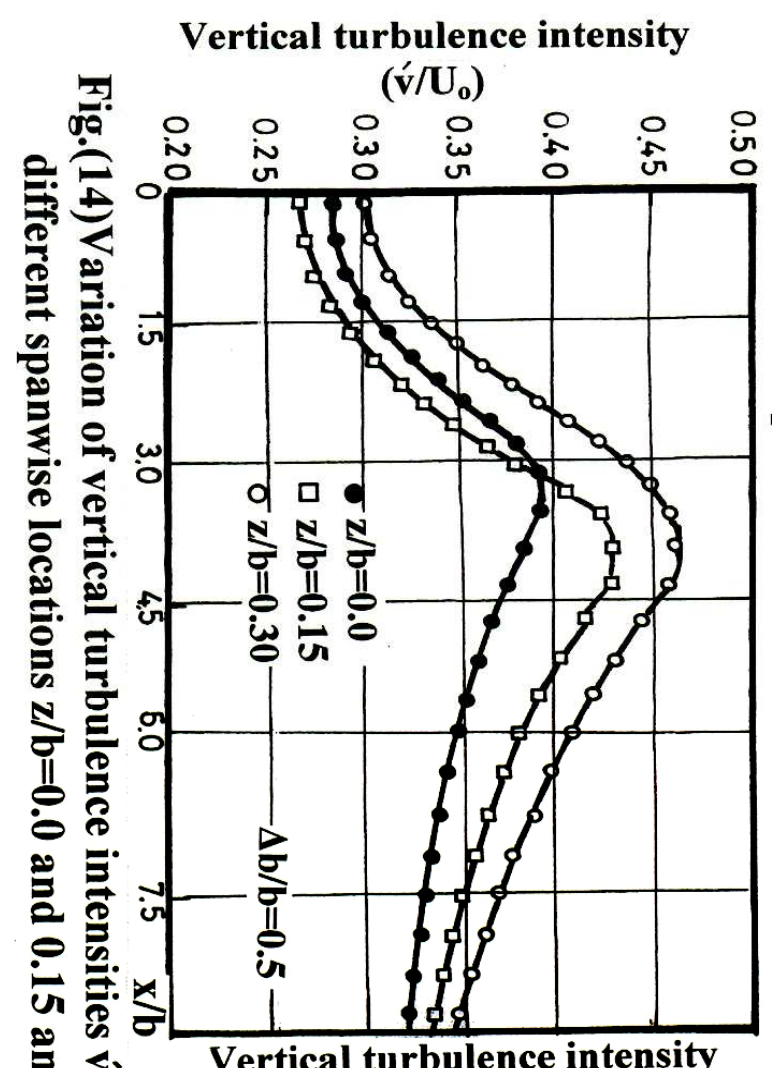

Streamwise turbulence intensity (ú/: $\left.\mathbf{U}_{\mathbf{o}}\right)$
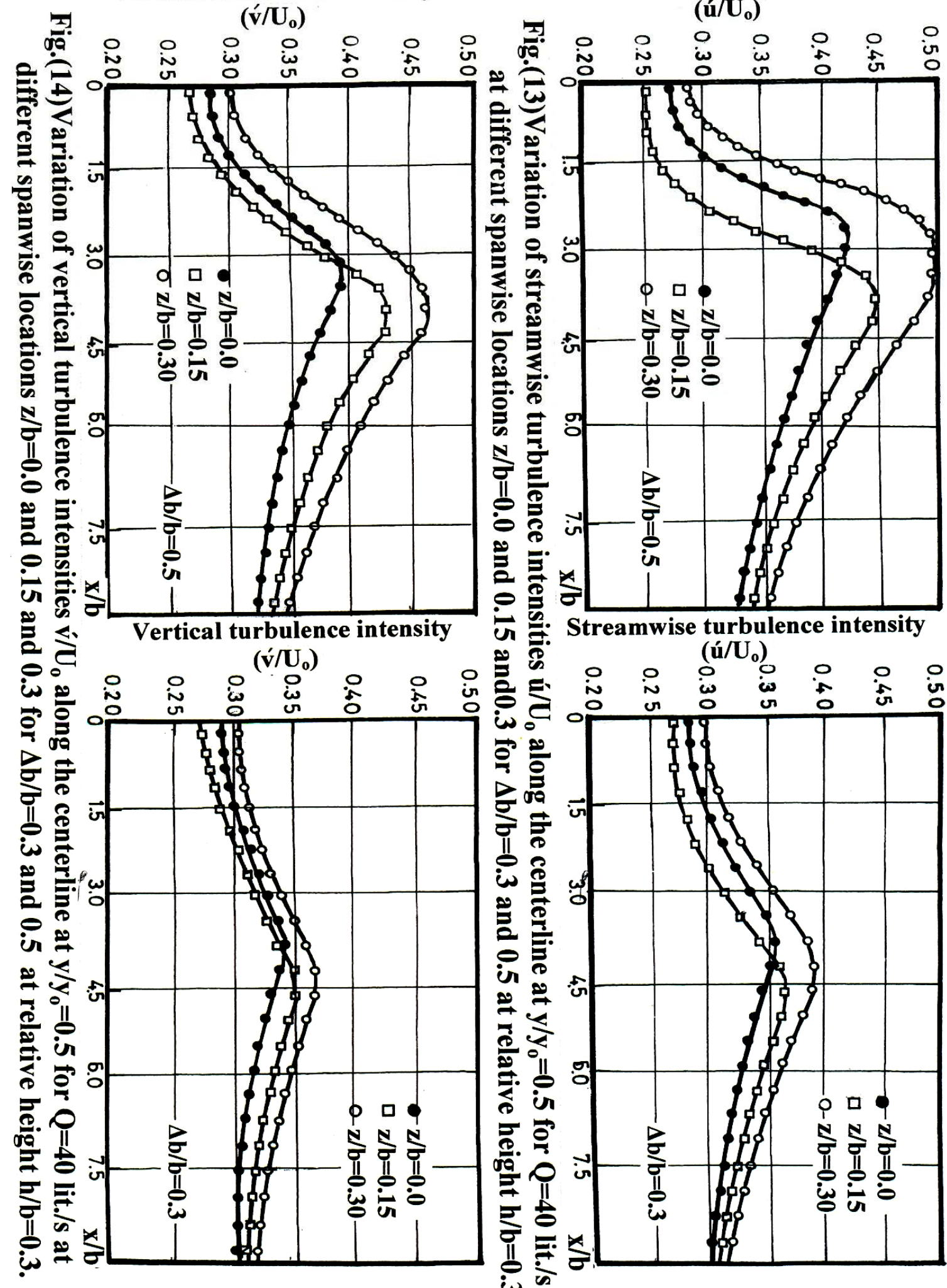

Streamwise turbulence intensity

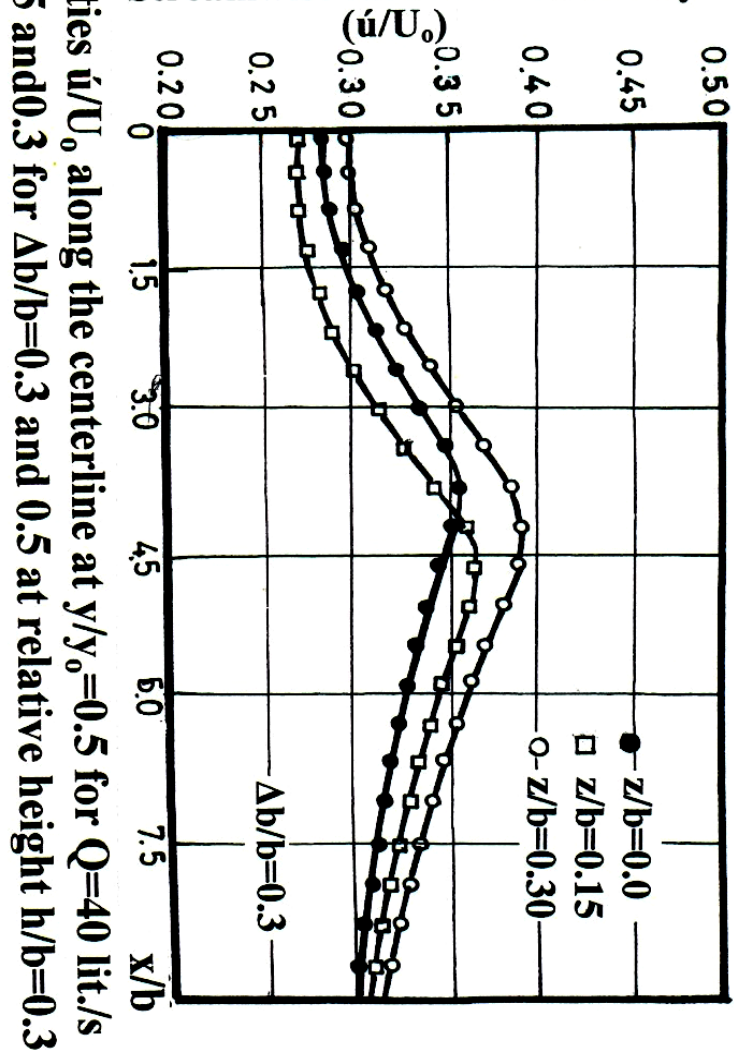



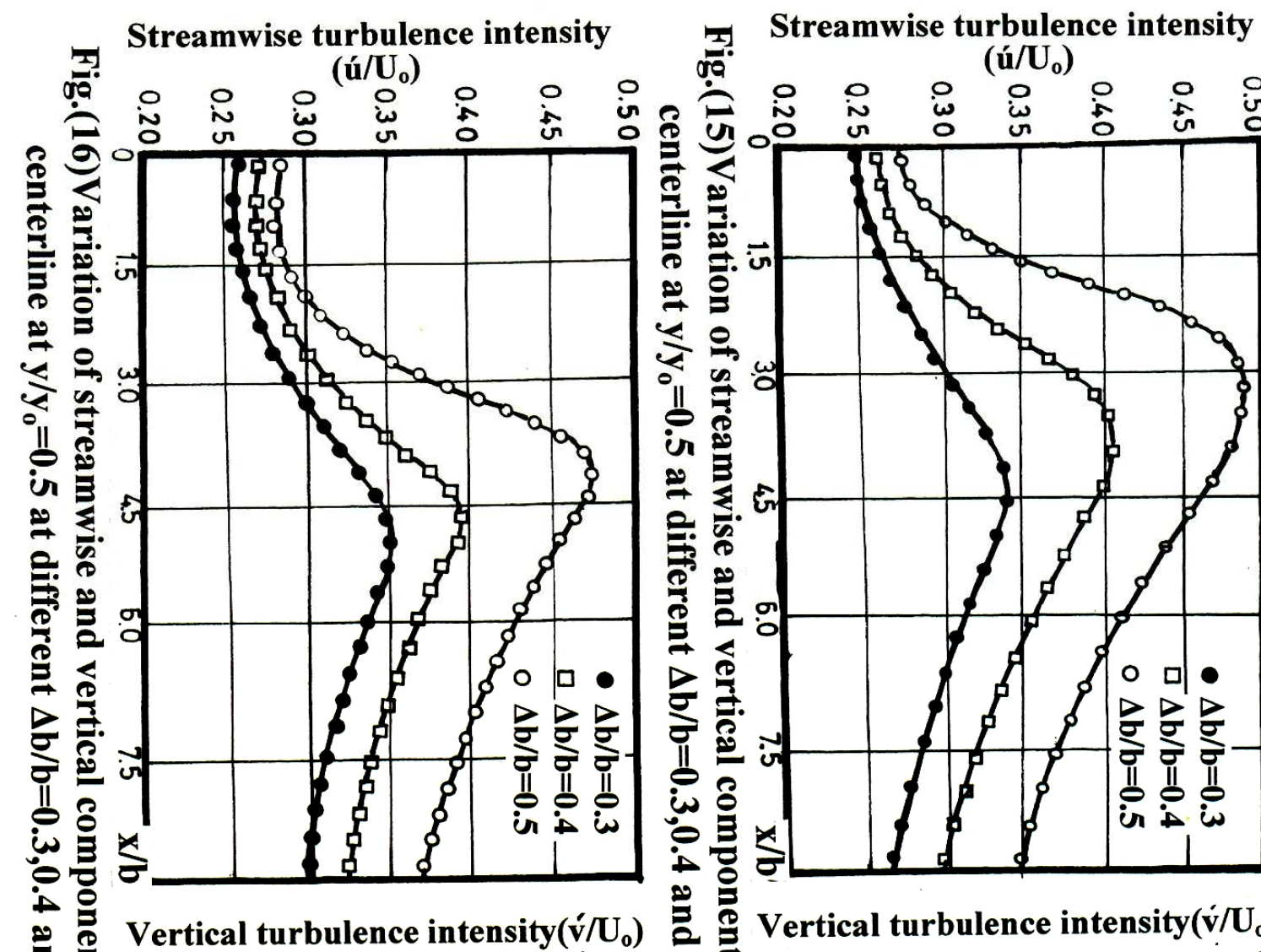

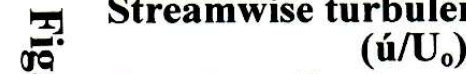

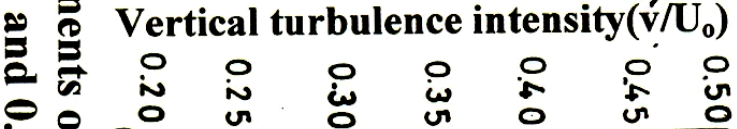
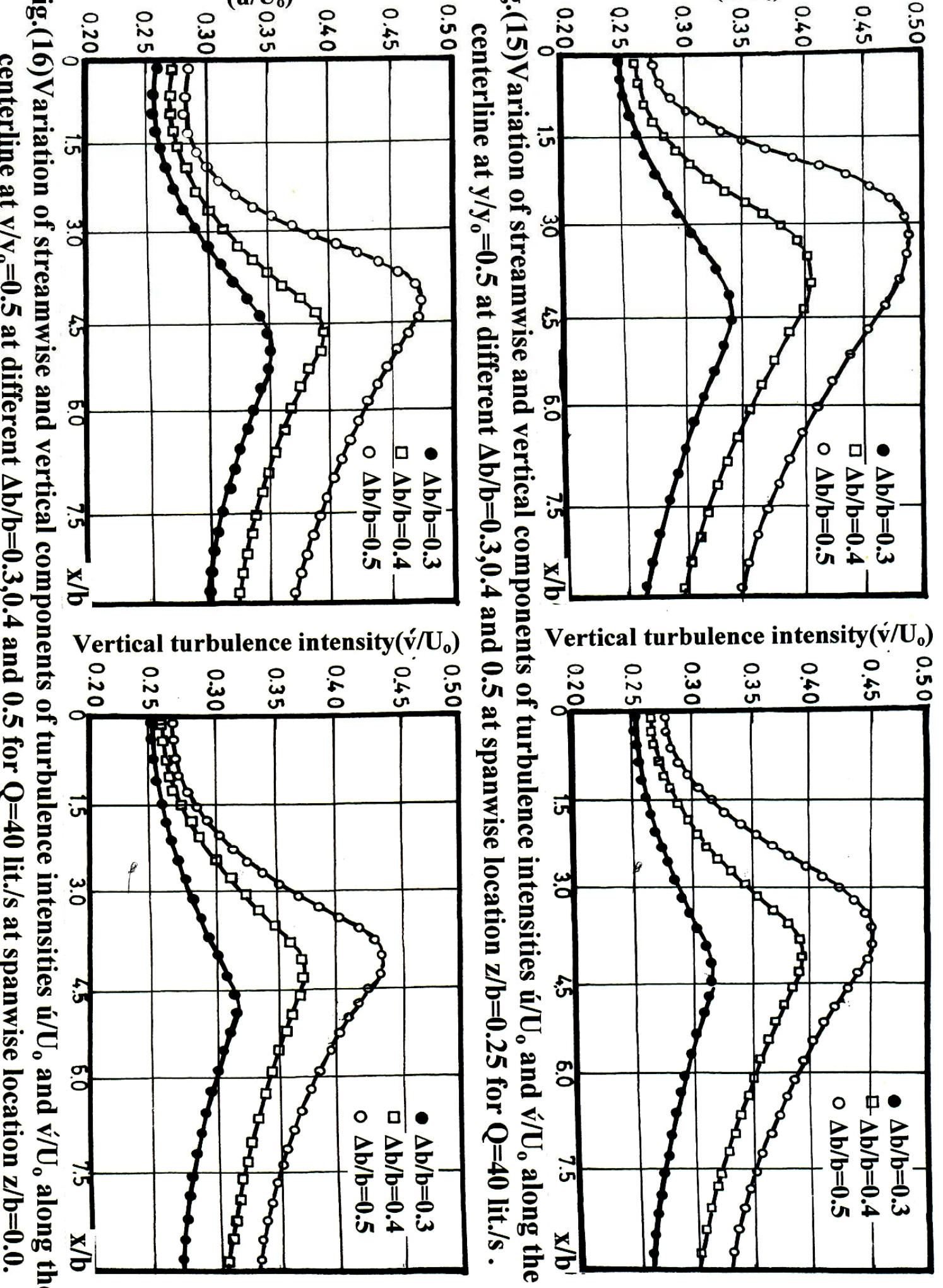